\title{
CARACTERIZAÇÃO E EVOLUÇÃO DE HEDENBERGUITA- HASTINGSITA-BIOTITA-GRANADA ORTOGNAISSE NA REGIÃO DA ZONA DE PALEO-SUTURA DE ALTEROSA, PORÇÃO SUL DO ORÓGENO BRASÍLIA MERIDIONAL
}

\author{
CHARACTERIZATION AND EVOLUTION OF HEDENBERGITE-HASTINGSITE-BIOTITE- \\ GARNET ORTHOGNEISS IN THE REGION OF THE ALTEROSA PALEO-SUTURE ZONE, \\ SOUTHERN PORTION OF SOUTHERN BRASÍLIA OROGEN
}

\section{Thaís Güitzlaf LEME", Guillermo Rafael Beltran NAVARRO², Antenor ZANARDO²,} Filipe Goulart LIMA ${ }^{3}$, Cibele Carolina MONTIBELLER ${ }^{1}$

${ }^{1}$ Pós-Graduação em Geociências e Meio Ambiente, Instituto de Geociências e Ciências Exatas, Departamento de Geologia, Universidade Estadual Paulista, Campus de Rio Claro. E-mail: thais.g.leme@unesp.br; cibele.cm@outlook.com

${ }^{2}$ Instituto de Geociências e Ciências Exatas, Departamento de Geologia, Universidade Estadual Paulista, Campus de Rio Claro. guillermo.navarro@unesp.br; antenor.zanardo@unesp.br

${ }^{3}$ Instituto de Geografia, Universidade Federal de Uberlândia, Campus de Monte Carmelo. E-mail: filipe.lima@ufu.br

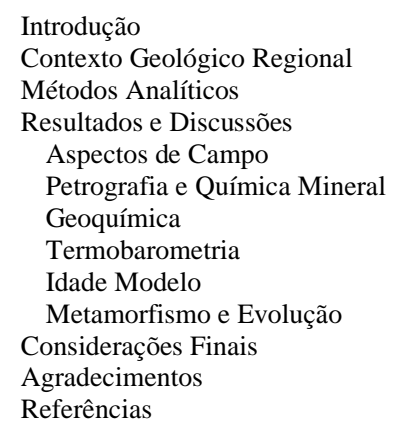

RESUMO - No sudoeste do estado de Minas Gerais, região do distrito de Santa Cruz do Prata, inserido num contexto de rochas de alta pressão atribuídas ao Grupo Araxá, na porção sul do Orógeno Brasília Meridional, foi registrada a ocorrência de um corpo de hedenberguita-hastingsita-biotita-granada ortognaisse, cuja associação mineral é pouco comum. Neste trabalho são apresentados dados de petrografia, química mineral, geoquímica, geotermobarometria e idade modelo da ocorrência. O ortognaisse configura um corpo lenticular, orientado segundo a direção E-W, paralelo à direção das zonas de cisalhamento regionais. Apresenta estrutura isotrópica a anisotrópica, podendo exibir domínios bem mais foliados e orientados, em consequência do maior grau de deformação. A associação mineral presente nas porções menos deformadas (andesina + ortoclásio + quartzo + granada + hedenberguita), as feições texturais e petrológicas em consonância com os dados químicos e isotópicos, sugerem um protólito de origem ígnea de idade paleoproterozoica, metamorfizado em fácies granulito (alta pressão). As condições de pressão e temperatura calculadas (em torno 11,0-10,5 kbar e 750$700^{\circ} \mathrm{C}$ ) correspondem ao reequilíbrio metamórfico regional. Os dados geoquímicos indicam características semelhantes à de rochas geradas em arcos magmáticos.

Palavras-chave: Faixa Brasília, Grupo Araxá, Cinturão de Cisalhamento Campo do Meio, Fácies granulito.

\begin{abstract}
In the southwest of Minas Gerais state, Santa Cruz do Prata district region, inserted in a context of high-pressure rocks attributed to the Araxá Group, in the southern portion of the Southern Brasillia Orogen, an occurrence of hedenbergite- hastingsitebiotite-garnet orthogneiss body was recorded, whose mineral association is uncommon. This paper presents petrography, mineral chemistry, geochemistry, geothermobarometry, and model age data of the occurrence. The orthogneiss configures a lenticular body, oriented according to the E-W direction, parallel to the direction of the regional shear zones. It has isotropic to anisotropic structure and it can show much more foliated and oriented domains, as result of the greater degree of deformation. The mineral association present in the less deformed portions (andesine + orthoclase + quartz + garnet + hedenbergite), the textural and petrological features in line with the chemical and isotopic data, suggest a paleoproterozoic igneous protolith, metamorphosed into granulite facies (high pressure). The calculated pressure and temperature conditions (around 11.0-10.5 kbar and $750-700^{\circ} \mathrm{C}$ ) correspond to the regional metamorphic re-equilibration. Geochemical data indicate characteristics similar to rocks generated in magmatic arcs.
\end{abstract}

Keywords: Brasília Belt, Araxá Group, Campo do Meio Shear Belt, Granulite facies.

\section{INTRODUÇÃO}

Orógenos colisionais são resultantes de processos tectônicos que sujeitam as rochas da crosta continental a metamorfismo, anatexia e deformação. As raízes de antigos orógenos são importantes registros de processos colisionais, e podem ser utilizadas como as principais fontes de informação de porções profundas da crosta para a compreensão da evolução geológica em regimes de margens convergentes (Pauly et al., 2016). 
Rochas de alta pressão (High Pressure - HP) são normalmente descritas em zonas internas de orógenos colisionais, e ocorrem em equilíbrio com elevadas condições de pressão e temperatura. Essas rochas representam remanescentes de zonas de espessamento crustal em ambientes de zonas de subdução e arcos continentais ou de duplicação crustal em uma colisão continental, compatíveis com o ambiente de crosta continental profunda (Harley, 1989, 1998; Bohlen, 1991; O’Brien \& Rötzler, 2003; Carswell \& Compagnoni, 2003; Chopin, 2003; Kelsey, 2008; Brown, 2009, 2014; Liou et al., 2009, 2014; Pauly et al., 2016; Zheng \& Chen, 2017).

No sudoeste do estado de Minas Gerais, região do distrito de Santa Cruz do Prata, foi descrita uma faixa de rochas de alta pressão atribuídas ao Grupo Araxá (Zona de PaleoSutura de Alterosa), na porção sul da Faixa Brasília Meridional (Zanardo, 1992, 2003; Del Lama, 1993; Del Lama et al., 1994; Zanardo et al., 2006; Leme, 2019; Leme et al., 2019). Inserido neste contexto, foi registrada a ocorrência de um corpo de hedenberguitahastingsita-biotita-granada ortognaisse (Leme, 2016), cuja associação mineral é pouco comum.

Neste trabalho são apresentados dados de petrografia, química mineral, geoquímica, geotermobarometria e idade modelo da ocorrência de hedenberguita-hastingsita-biotitagranada ortognaisse, com o objetivo de caracterizar a ocorrência e contribuir para as discussões acerca da evolução da Zona de PaleoSutura de Alterosa (Zanardo et al., 2006).

\section{CONTEXTO GEOLÓGICO REGIONAL}

A área de estudo está localizada no sudoeste do estado de Minas Gerais, a nordeste de Santa Cruz do Prata, distrito do município de Guaranésia. Situa-se na porção sul da Província Estrutural Tocantins (Almeida, 1967), na parte sul da Faixa Brasília Meridional (Almeida, 1977), próximo ao contato entre o Complexo Guaxupé (a sul), e rochas correlacionadas ao Grupo Araxá (a norte), na região do Cinturão de Cisalhamento Campo do Meio (Cavalcante et al., 1979; Zanardo, 1992; Morales, 1993) (Figura 1).

Nesta região são reconhecidas unidades litoestratigráficas que compõem dois blocos crustais justapostos, a norte o Cráton do São Francisco, e a sul, o Bloco ou Placa Paranapanema, amalgamados durante a orogênese brasiliana no Neoproterozoico (Almeida et al., 1980; Haralyi \& Hasui, 1982; Haralyi et al., 1985; Hasui, 2010; Valeriano, 2017).

Os limites dos blocos são definidos por grandes descontinuidades gravimétricas (anomalias tipo Bouguer) e correspondem a uma faixa de deformação intensa, que define a Zona de Paleo-Sutura de Alterosa, representada por litotipos atribuídos ao Grupo Araxá (Almeida et al., 1980; Haralyi \& Hasui, 1982; Haralyi et al., 1985; Zanardo, 1992; Morales, 1993; Malagutti Filho et al., 1996; Zanardo et al., 1996, 2006; Hasui, 2010; Valeriano, 2017).

O Grupo Araxá nessa região, atribuído por outros autores, como Cavalcante et al. (1979) ao Complexo Campos Gerais e por Trouw et al. (1984) ao Grupo Andrelândia, aflora como uma faixa estruturada segundo a direção E-W a WNW-ESE, a norte da exposição do Complexo Guaxupé (porção norte da Nappe Socorro-Guaxupé, Campos Neto \& Caby, 1999, 2000; Campos Neto et al., 2011) e a sul da exposição do Complexo Barbacena.

Essa faixa de rochas é constituída por metassedimentos pelíticos a psamo-pelíticos, com intercalações de ortognaisses e granitoides, e intercalações de rochas metamáficas e metaultramáficas, metamorfisados em condições de fácies anfibolito a granulito/eclogito, no campo de estabilidade da cianita (Zanardo, 1992, 2003; Del Lama, 1993; Del Lama et al., 1994; Zanardo et al., 1996, 2006; Leme, 2019; Leme et al., 2019).

A sequência metassedimentar é composta dominantemente por xistos e xistos feldspáticos com ou sem granada e cianita; muscovita e/ou biotita quartzitos e quartzo-xistos com ou sem granada e cianita; e por granada e/ou biotita gnaisses quartzosos a aluminosos com ou sem cianita. As intercalações de ortognaisses e granitoides incluem corpos tabulares a lenticulares com dimensões que podem variar de alguns metros a até $2,0 \mathrm{~km}$, de composição sienogranítica a tonalítica, predominando monzogranitos, cujos minerais máficos dominantes são biotita e anfibólio (Zanardo, 1992; 2003; Morales, 1993; Del Lama, 1993; Zanardo et al., 1996, 2006; Godoy et al., 1999). As rochas metamáficas e metaultramáficas tendem a concentrar-se na porção norte do Grupo Araxá, e são atribuídas a uma sequência ofiolítica, que ocorre sob a forma de corpos lenticulares, intensamente tectonizados (Soares et al., 1990; Zanardo, 1992, 2003; Zanardo et al., 1996; Lima, 2014). De acordo com Zanardo (1992, 2003), 
pode ser reconhecido um zoneamento metamórfico, com aumento de temperatura e pressão para sul, delimitado pelas zonas de cisalhamento.

Na porção mais meridional dessa faixa de rochas atribuídas ao Grupo Araxá, logo a norte da Zona de Cisalhamento Varginha, foram descritas ocorrências de rochas granulíticas de alta pressão (Zanardo, 1992; Del Lama, 1993; Del Lama et al., 1994; Leme, 2019; Leme et al., 2019), constituídas dominantemente por granada, clinopiroxênio, plagioclásio e anfibólio, às vezes com texturas simplectíticas e coroníticas, interpretadas como retroeclogitos (Leme, 2019; Leme et al., 2019). No contexto dessas rochas de HP, foi registrada a ocorrência de um corpo de hedenberguitahastingsita-biotita-granada ortognaisse, cuja associação mineral é pouco comum e representa 0 objeto de estudo deste trabalho.

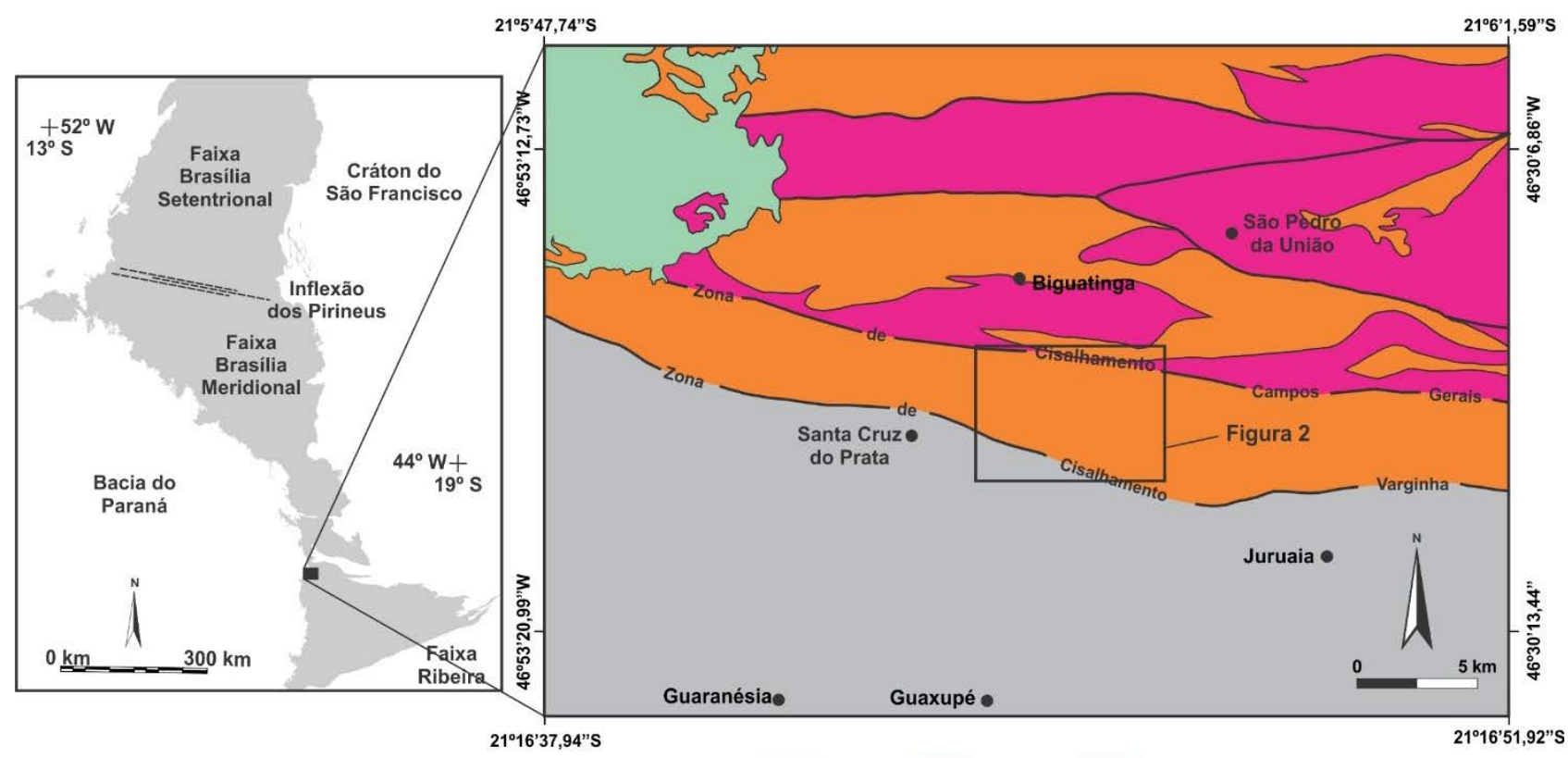

1

Figura 1 - Mapa geológico da região da área de estudo, com destaque para a localização da área de estudo na Faixa Brasília. I) Depósitos sedimentares e rochas básicas fanerozoicas atribuídas a Bacia do Paraná. Grupo Araxá: II) Sequência metassedimentar psamo-pelítica. III) Ortognaisses e granitoides de composição sienogranítica a tonalítica. IV) Complexo Guaxupé (ortopiroxênio gnaisses, quartzo mangeritos, gnaisses charnockíticos e mais raramente gnaisses graníticos) (Compilado de Zanardo, 1992; Zanardo et al., 2006).

\section{MÉTODOS ANALÍTICOS}

Amostras de hedenberguita-hastingsitabiotita-granada ortognaisse foram selecionadas para análise petrográfica, análises de química mineral, geoquímica de rocha total, cálculos geotermobarométricos e análise isotópica $\mathrm{Sm} / \mathrm{Nd}$ para idade modelo em rocha total.

As análises de química mineral foram realizadas no Laboratório de Microssonda Eletrônica do Departamento de Geologia do Instituto de Geociências e Ciências Exatas, Unesp - Campus de Rio Claro, por meio de microssonda eletrônica da marca JEOL modelo JXA-8230 superprobe. As condições analíticas foram de aceleração de $15 \mathrm{kV}$, corrente de 20,4 $\mathrm{n} \AA$ e diâmetro do feixe de $10 \mu \mathrm{m}$, para a realização de análises pontuais e em perfis em cristais de granada, plagioclásio, feldspato potássico, clinopiroxênio, anfibólio e biotita, escolhidos por critérios petrográficos de acordo com a paragênese de interesse.

Os cálculos da atividade mineral das fases analisadas e das fórmulas estruturais dos minerais foram realizados pelo programa $A X$ (disponível em: http://www.ccp14.ac.uk/ccp/webmirrors/crush/astaff/holland/ax.html) desenvolvido por Tim Holland e pelo programa MINPET versão 2.02 (Richard, 1995). Os cálculos termobarométricos foram realizados utilizandose o software THERMOCALC 3.26, modo Average-PT (Powell \& Holland, 1994).

As análises geoquímicas de rocha total foram feitas pelo Laboratório Acme (Analytical Laboratories LTD, Vancouver, Canadá) e foram realizadas por meio de Espectrometria de Emissão Atômica por Plasma Acoplado Indutivamente (ICP-AES), após fusão utilizando metaborato/ tetraborato de lítio e digestão em ácido nítrico diluído, e a perda ao fogo (LOI) determinada por 
método termogravimétrico a $1.000^{\circ} \mathrm{C}$ por quatro horas, e por Espectrometria de Massa em Plasma Acoplado Indutivamente (ICP-MS), após fusão utilizando metaborato/tetraborato de lítio e digestão em ácido nítrico. Para a manipulação dos dados geoquímicos e elaboração de diagramas foi utilizado o programa MINPET versão 2.02.

Os estudos isotópicos $\mathrm{Sm} / \mathrm{Nd}$ para determinação de Idade Modelo (TDM) em rocha total foram realizados no Laboratório de Geocronologia e Isótopos Radiogênicos (LAGIR), da Faculdade de Geologia, da
Universidade Estadual do Rio de Janeiro, utilizando-se o método de Valeriano et al. (2009).

As leituras das razões foram feitas em Espectrômetro de Massa por ionização termal (TIMS) da marca Finnigan TRITON-TI. A razão ${ }^{143} \mathrm{Nd} /{ }^{144} \mathrm{Nd}$ foi normalizada pelo padrão de $\mathrm{La}$ Jolla $\left({ }^{146} \mathrm{Nd} /{ }^{144} \mathrm{Nd}\right.$ de 0,7219$)$. A idade modelo $\mathrm{T}_{\mathrm{DM}}$ foi calculada utilizando-se o modelo de De Paolo (1981).

As abreviações minerais utilizadas neste trabalho seguem a proposta de Whitney \& Evans (2010).

\section{RESULTADOS E DISCUSSÕES}

\section{Aspectos de Campo}

A área de estudo está localizada a norte da Zona de Cisalhamento Varginha, na porção meridional da faixa de rochas atribuídas ao Grupo Araxá, na região do Cinturão de Cisalhamento Campo do Meio. A localização do corpo de hedenberguita-hastingsita-biotitagranada ortognaisse e das amostras estudadas é apresentada na figura 2 .
O hedenberguita-hastingsita-biotita-granada ortognaisse ocorre sob a forma de um corpo lenticular, com aproximadamente $4,0 \mathrm{~km}$ de extensão, orientado próximo à direção E-W (Figura 2), paralelo a subparalelo à direção das zonas de cisalhamento regionais (E-W a WNWESE), e aflora principalmente sob a forma de blocos isolados com dimensões que variam de 0,5 a 2,0 m de diâmetro (Figuras 3A, B).

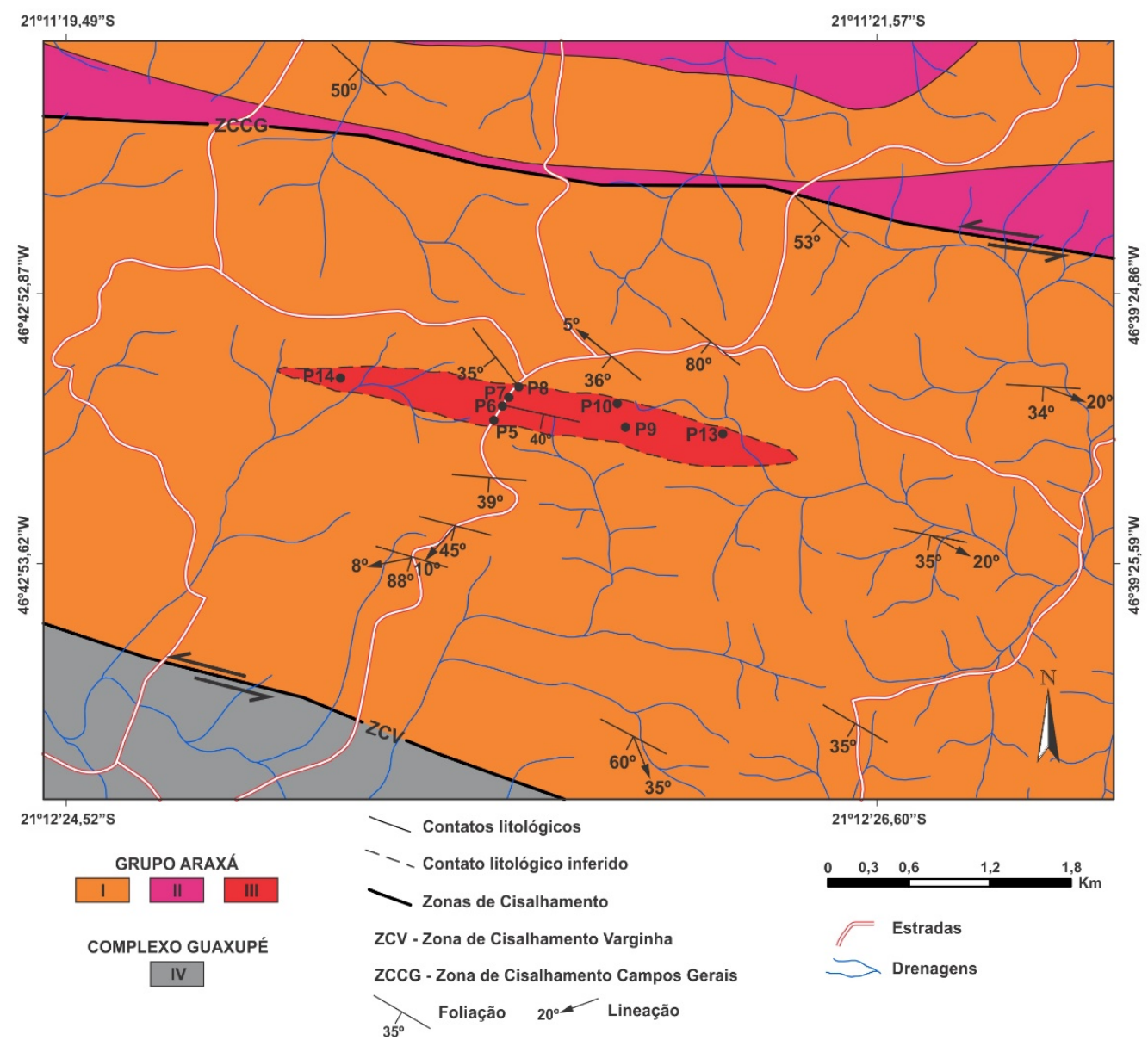

Figura 2 - Detalhe do mapa geológico mostrando o corpo de hedenberguita-hastingsita-biotita-granada ortognaisse e a localização das amostras estudadas. Grupo Araxá: I) Sequência metassedimentar psamo-pelítica; II) Ortognaisses e granitoides de composição sienogranítica a tonalítica; III) Corpo de hedenberguita-hastingsita-biotita-granada ortognaisse de composição monzogranítica a granodiorítica. IV) Complexo Guaxupé (ortopiroxênio gnaisses, quartzo mangeritos, gnaisses charnockíticos e mais raramente gnaisses graníticos) (Compilado de Zanardo 1992; Zanardo et al., 2006; Modificado de Leme, 2016). 
Este corpo de ortognaisse ocorre encaixado em metassedimentos psamo-pelíticos com granada, cianita, ortoclásio e rutilo (cianitagranada gnaisses, cianita-granada gnaisses quartzosos, cianita-granada xistos, cianitagranada quartzitos, granada quartzitos e granada gnaisses), entre as zonas de cisalhamento Varginha (a sul) e Campo Gerais (a norte) (Figura 2).

As relações de contato entre o ortognaisse e as rochas encaixantes não foram observadas em campo.

O ortognaisse apresenta coloração cinza claro,
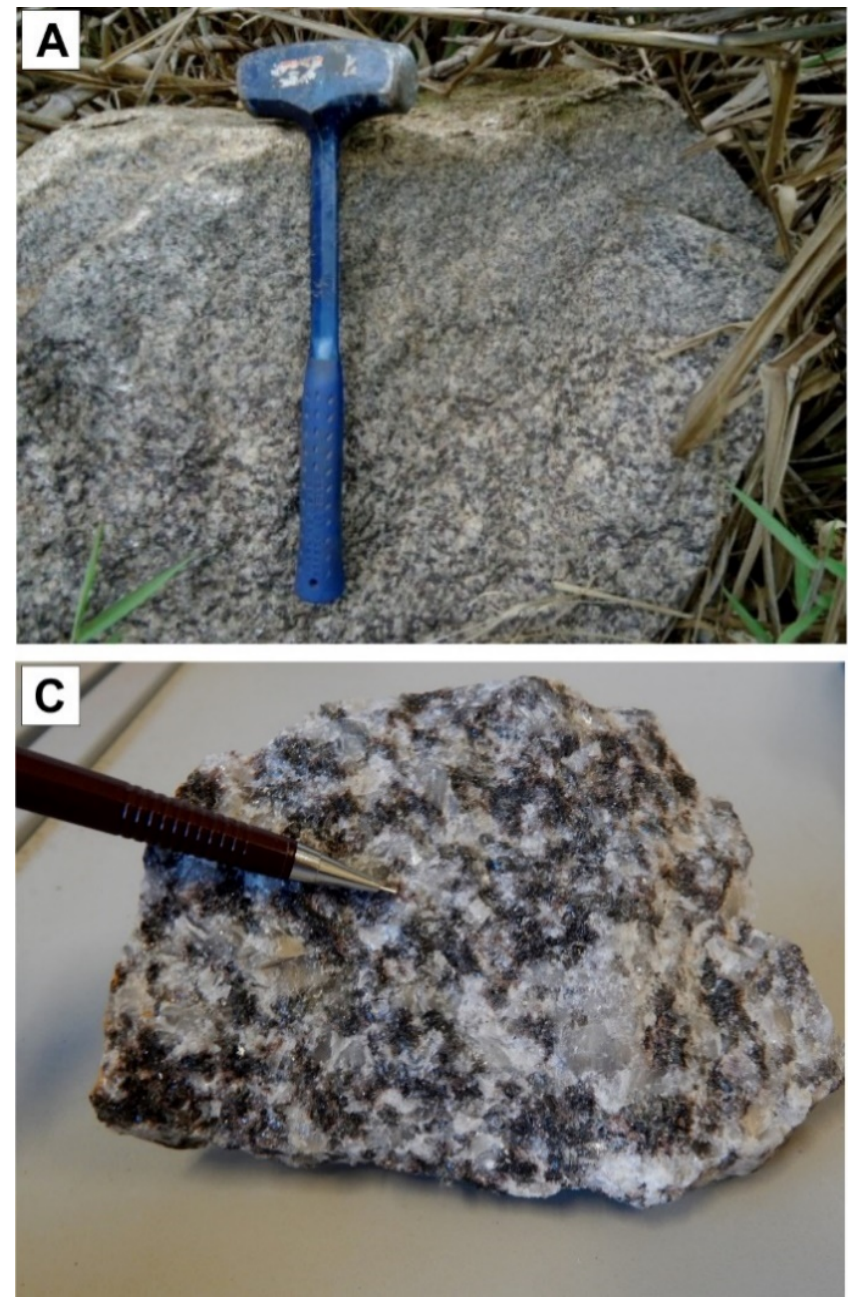

é leucocrático e mostra diferentes graus de anisotropia, com predomínio de estrutura isotrópica (Figura 3C) e textura granular hipidiomórfica/alotriomórfica a granoblástica, de granulação média a grossa nas porções centrais do corpo, tendendo a termos mais anisotrópicos (Figura 3D) e textura granoblástica inequigranular de granulação média a fina para as bordas do corpo. A anisotropia da rocha é marcada por bandamento gnáissico descontínuo submilimétrico, constituído pela alternância de leitos descontínuos de minerais félsicos e minerais máficos orientados.
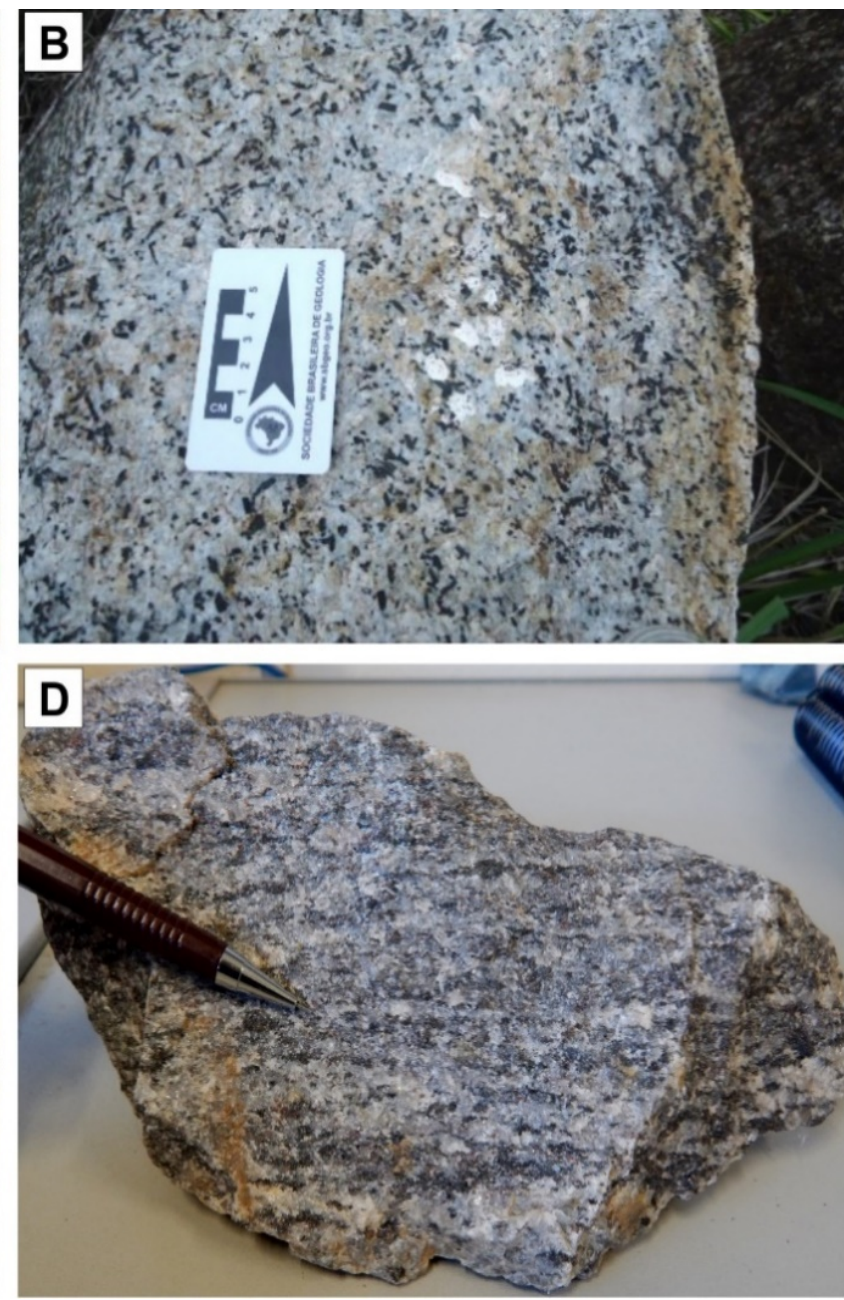

Figura 3 - Aspectos macroscópicos do hedenberguita-hastingsita-biotita-granada ortognaisse. A) e B) Tipo principal de ocorrência na forma de matacões do ortognaisse; $\mathbf{C}$ ) Estrutura isotrópica do ortognaisse representada nas porções centrais do corpo; D) Estrutura anisotrópica com bandamento gnáissico submilimétrico descontínuo representada principalmente em direção às bordas do corpo de ortognaisse.

\section{Petrografia e Química Mineral}

Nesta seção são descritos os principais aspectos microscópicos e mineralógicos das amostras estudadas. Baseado nas feições texturais e mineralógicas, cinco amostras do corpo de hedenberguita-hastingsita-biotitagranada ortognaisse foram selecionadas para análise de química mineral de elementos maiores. Os resultados representativos das análises de química mineral e o respectivo conteúdo de átomos por unidade de fórmula (a.p.u.f) são apresentados nas tabelas suplementares - Apêndice (Tabelas 1, 2, 3, 4 e 5).

As rochas que constituem o corpo de hedenberguita-hastingsita-biotita-granada ortognaisse apresentam grau variado de anisotropia, resultando em estrutura gnáissica com diferentes estágios de desenvolvimento, devido à variação 
do grau de deformação. A estrutura da rocha é marcada por fraca orientação dos cristais de feldspato potássico e plagioclásio, e por orientação mais pronunciada dos cristais de quartzo e dos agregados constituídos por granada, anfibólio, biotita e clinopiroxênio. A textura é predominantemente granoblástica inequigranular poligonal a lobulada, com domínios descontínuos inequigranulares constituídos por granada, biotita e anfibólio. Localmente preserva textura primária granular hipidiomórfica a alotriomórfica.

A mineralogia das rochas que compõem o corpo de ortognaisse em estudo é constituída por plagioclásio (30-35\%), quartzo (20-25\%), feldspato potássico (15-20\%), granada (5-10\%), biotita (5-10\%), anfibólio (5-7\%), e clinopiroxênio (0-5\%), com ilmenita, titanita, apatita, zircão, allanita como minerais acessórios $(<1 \%)$, além de traços de epidoto e carbonato.

O plagioclásio ( $\left.\mathrm{An}_{12,30-35,26}\right)$ (Figura 4A) ocorre em leitos irregulares descontínuos granoblásticos associados ao quartzo e ao feldspato potássico. Os cristais são dominantemente subédricos a anédricos, com dimensões que podem atingir até 5,0 mm.
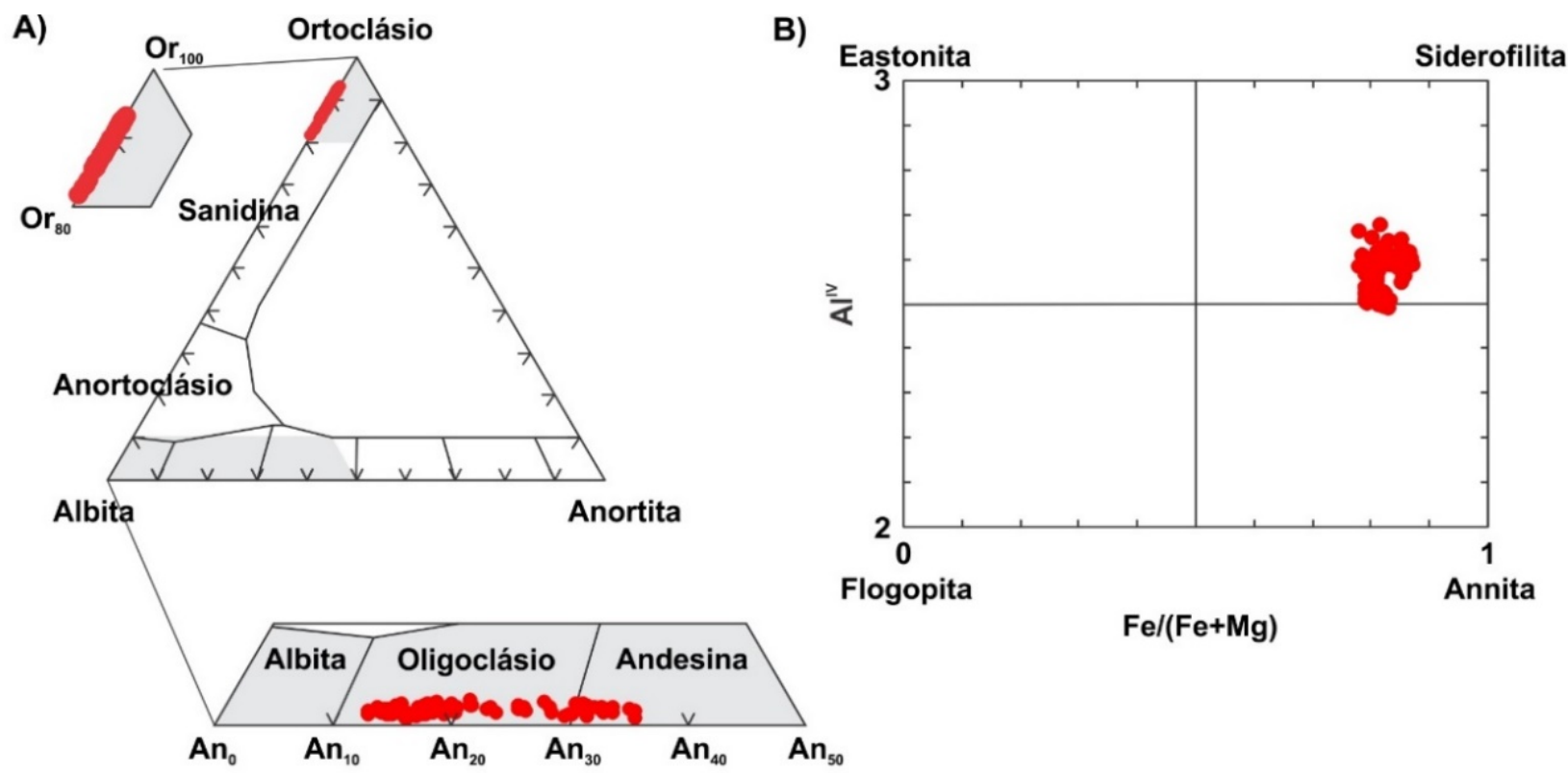

C)

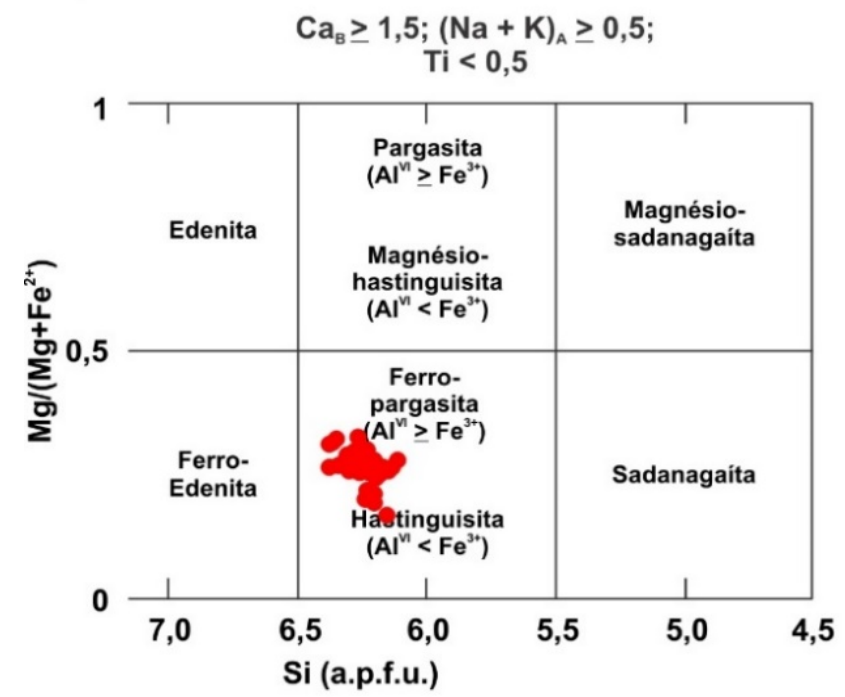

D)

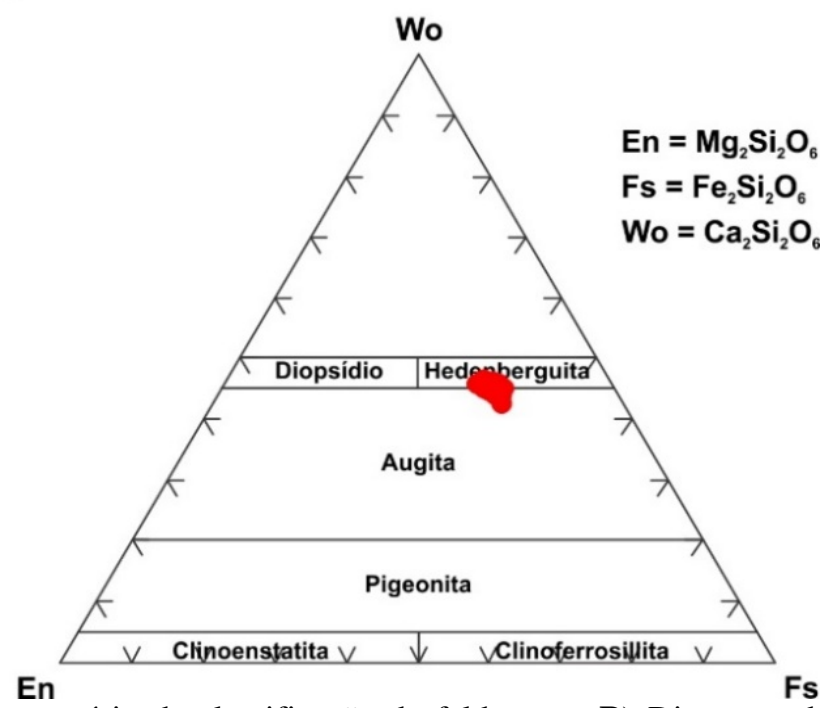

Figura 4 - Gráficos de classificação mineral. A) Diagrama ternário de classificação de feldspatos; B) Diagrama de classificação de biotita; C) Diagrama de classificação de anfibólios cálcicos (Modificado de Leake et al., 1997); D) Diagrama ternário Ca-Mg-Fe para classificação de piroxênios (Morimoto, 1988).

Exibem textura antipertítica e mirmequítica (Figuras 5A, B), e podem apresentar bordas mais sódicas. Alguns cristais apresentam inclusões de quartzo (quartzo em gotas), e podem mostrar-se corroídos por feldspato potássico. Em algumas porções, o plagioclásio forma agregados 
granulares com contatos poligonais, concentrados em domínios (Figuras 5C, D) e envoltos por textura reliquiar ígnea. O feldspato potássico (ortoclásio e microclínio), assim como o plagioclásio, ocorre concentrado em domínios descontínuos. Os cristais são anédricos a dominantemente subédricos, podem atingir dimensões de
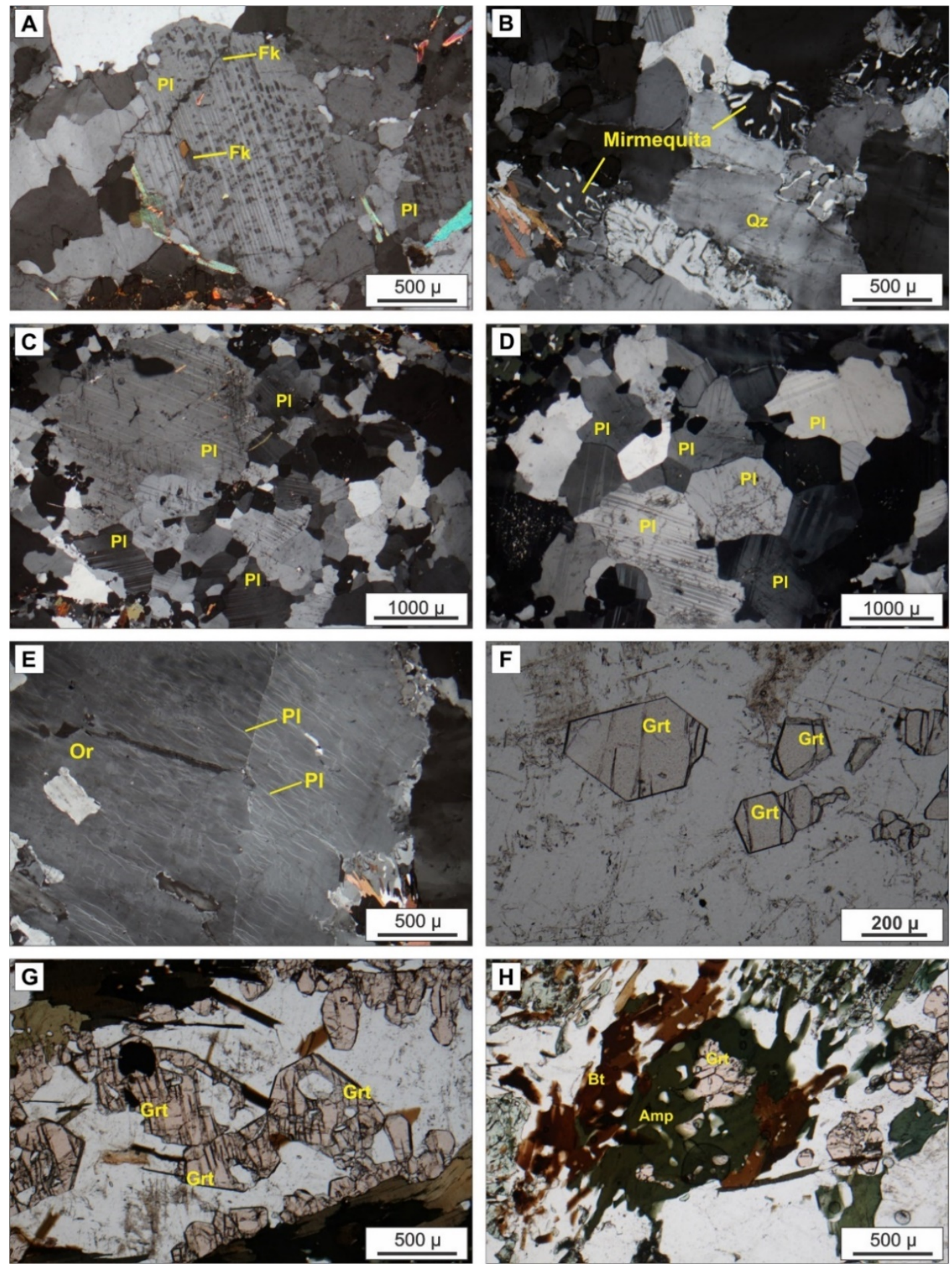

Figura 5 - Aspectos petrográficos do hedenberguita-hastingsita-biotita-granada ortognaisse. A) Cristal de plagioclásio antipertítico (Polarizadores cruzados); B) Cristal de plagioclásio com intercrescimento venular de quartzo (textura mirmequítica) (Polarizadores cruzados); C e D) Agregados granulares de cristais de plagioclásio com contatos poligonais (Polarizadores cruzados); E) Cristal de ortoclásio pertítico (Polarizadores cruzados); F) Cristais euédricos de granada isolados com contatos poligonais (Polarizadores paralelos); G) Cristais anédricos de granada com bordas lobuladas (Polarizadores paralelos); H) Cristal de granada parcialmente substituído por anfibólio e biotita (Polarizadores paralelos). Amp: anfibólio, Bt: biotita, Fk: feldspato potássico, Grt: Granada, Or: ortoclásio, Pl: plagioclásio, Qz: quartzo. 
O feldspato potássico mostra composição semelhante em todas as amostras, e varia em cerca de $10 \%$ na concentração de ortoclásio (Or82,98-93,33) (Figura 4A).

$\mathrm{O}$ quartzo ocorre sob a forma de cristais anédricos, com dimensões que podem atingir 5,0 $\mathrm{mm}$. Ocorre em domínios lenticulares a irregulares (associado aos feldspatos), e exibe contatos predominantemente lobulados a engrenados. Os cristais apresentam extinção ondulante leve a moderada, recristalização, recuperação e deformação em bandas.

A granada ocorre como cristais subédricos a euédricos isolados (Figura 5F) e/ou sob a forma de cristais e agregados anédricos a arredondados (Figura 5G), com dimensões que variam de 0,4 $\mathrm{mm}$ a 3,0 mm. Pode apresentar-se corroída por biotita e anfibólio (Figura $5 \mathrm{H}$ ), e localmente forma coroas na borda de cristais de plagioclásio (Figura 6A).
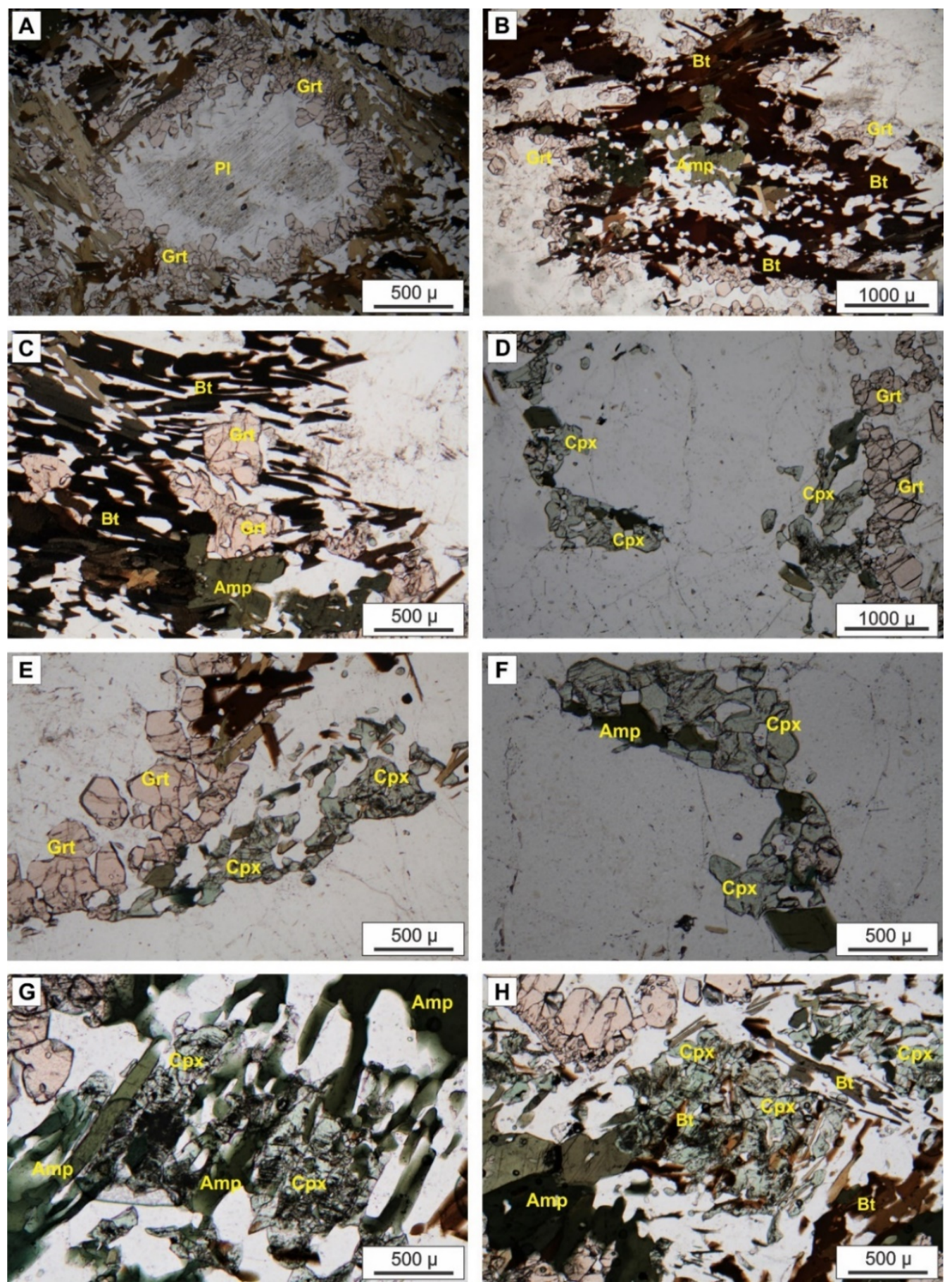

Figura 6 - Aspectos petrográficos do hedenberguita-hastingsita-biotita-granada ortognaisse. A) Cristal de plagioclásio exibindo coroa de cristais de granada (Polarizadores paralelos); B e C) Cristais de biotita substituindo cristais de granada e de anfibólio (Polarizadores paralelos); D e E) Cristais de clinopiroxênio associados a cristais de granada (Polarizadores paralelos); F e G) Cristais de clinopiroxênio parcialmente substituídos por anfibólio (Polarizadores paralelos); H) Cristais de clinopiroxênio parcialmente substituídos por biotita (Polarizadores paralelos). Amp: anfibólio, Bt: biotita, Cpx: clinopiroxênio, Grt: Granada, Pl: plagioclásio. 
A composição da granada é dominada pela molécula de almandina (Alm59,42-72,46), seguida por proporções intermediárias de grossulária (Grs7,93-28,57), e menores proporções de piropo (Prp2,48-5,67), andradita $\left(\mathrm{Adr}_{<1,00-13,00) \quad \text { e }}\right.$ espessartita (Sps1,07-2,82).
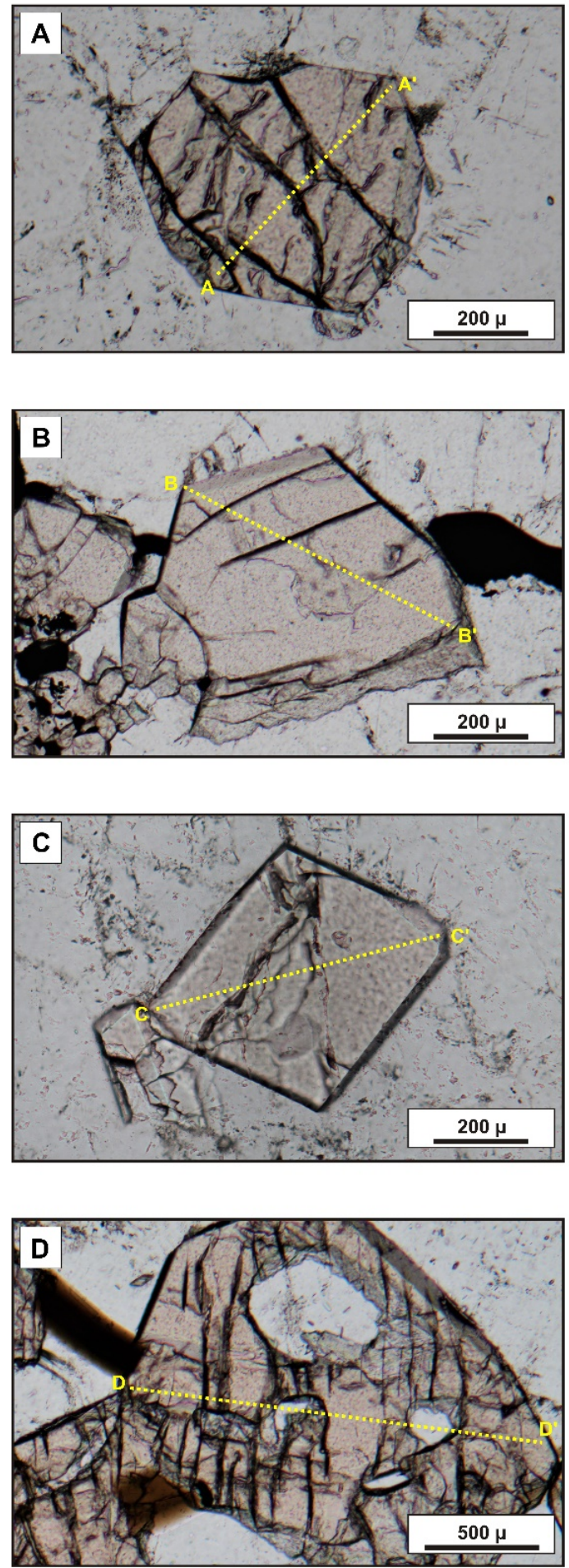

A composição química mostra perfis composicionais quase planos (retos) e homogêneos, marcados por sutil zoneamento químico, definido por leve diminuição de $\mathrm{Fe}^{2+} \mathrm{e}$ $\mathrm{Mg}$ e fraco aumento de $\mathrm{Ca}$ em direção às bordas dos cristais (Figura 7).
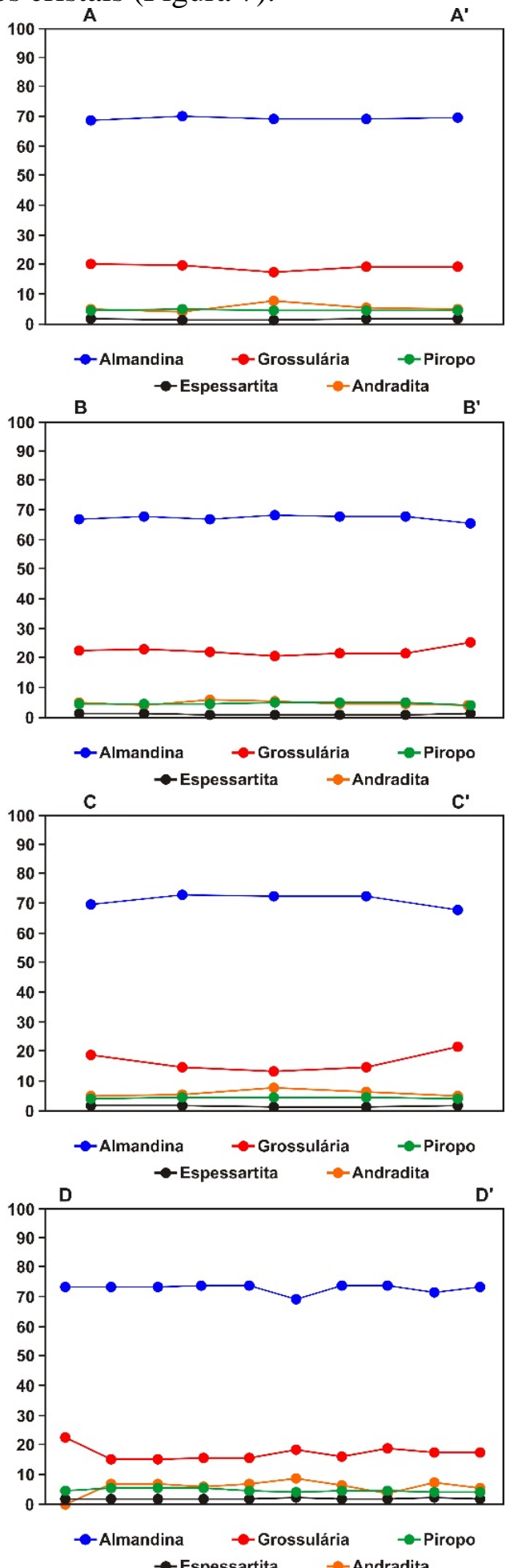

Figura 7 - Perfis composicionais de cristais de granada analisados.

A biotita é quimicamente classificada como siderofilita (Figura 4B), ocorre como pequenas palhetas anédricas e exibe pleocroísmo predominantemente marrom amarelado marrom escuro - castanho claro. Mostra-se na 0,210 , teor de $\mathrm{Al}^{\mathrm{IV}}$ relativamente alto, entre 2,490 
e 2,729 a.p.u.f., assim como o conteúdo de Ti, que varia entre 0,290 e 0,614 a.p.u.f e conteúdo de $\mathrm{Al}^{\mathrm{VI}}$, entre 0,053 e 0,527 a.p.u.f.

O anfibólio apresenta composição cálcica $\left(\mathrm{Ca}_{\mathrm{B}} \geq 1,5, \mathrm{Na}_{\mathrm{A}}+\mathrm{K}_{\mathrm{A}} \geq 0,5, \mathrm{Ti} \leq 0,5\right.$ e $\left.\mathrm{Si}<6,5\right)$ e é classificado como hastingsita/ferro pargasita no diagrama de Leake et al. (1997) (Figura 4C). Ocorre sob a forma de cristais euédricos a anédricos associados principalmente ao clinopiroxênio, e sugerem ser produto de substituição desse mineral (Figuras 6D, F, G). O anfibólio pode constituir coroas quase a totalmente completas em torno dos cristais de granada e de clinopiroxênio. Localmente ocorre alterado para biotita. Quimicamente, os cristais apresentam composição relativamente homogênea em todas as amostras, com razão $\mathrm{Mg} /(\mathrm{Mg}+\mathrm{Fe})$ variando entre 0,131 a 0,241 , conteúdo de $\mathrm{Al}^{\mathrm{IV}}$ entre 1,441 e 1,761 a.p.u.f., de $\mathrm{Al}^{\mathrm{VI}}$ entre 0,427 a 0,847 a.p.u.f., e de Ti variando entre 0,027 e 0,271 a.p.u.f.

O clinopiroxênio é classificado como hedenberguita $\quad\left(\mathrm{Wo}_{42,64-46,45} \mathrm{En}_{15,57-18,78} \mathrm{Fs}_{35,51-}\right.$ 40,40) (Figura 4D) e ocorre sob a forma de cristais subédricos a anédricos, com dimensões que variam da ordem de 0,5 a $1,5 \mathrm{~mm}$. Apresenta bordas corroídas, em geral associado aos cristais de granada (Figuras 6D, E), e ocorre parcialmente substituído por anfibólio (Figuras 6F, G) e mais raramente por biotita (Figura 6H). Os cristais apresentam conteúdos de Mg variando de 0,302 a 0,381 a.p.u.f. e de $\mathrm{Fe}^{2+}$ de 0,693 a 0,807 a.p.u.f. Os teores de Ca variam entre 0,808 e 0,931 a.p.u.f., e 0,031 a 0,139 a.p.u.f. de Al.

Os cristais de titanita possuem dimensões médias de $0,2 \mathrm{~mm}$, são anédricos e ocorrem predominantemente associados à biotita; localmente formam coroas em opacos. Os minerais opacos, zircão, apatita e allanita, ocorrem sob a forma de cristais subédricos a anédricos, dispersos pela lâmina, com dimensões inferiores a $0,3 \mathrm{~mm}$. A allanita ocorre associada ao epidoto. O epidoto e o carbonato ocorrem como minerais secundários, produto de alteração do clinopiroxênio e plagioclásio.

\section{Geoquímica}

Foram selecionadas sete amostras para análise geoquímica de rocha total correspondentes ao corpo de hedenberguita-hastingsita-biotita-granada ortognaisse. As amostras analisadas e os resultados das análises são apresentados na tabela 1.

As amostras do ortognaisse apresentam pequena variação no conteúdo de elementos maiores $\left(\mathrm{SiO}_{2}-67,94\right.$ a 70,13\%, $\mathrm{TiO}_{2}-0,58$ a $0,82 \%, \mathrm{Al}_{2} \mathrm{O}_{3}-12,63$ а $13,81 \%, \mathrm{Fe}_{2} \mathrm{O}_{3 \mathrm{~T}}-5,66$ а $7,77 \%, \mathrm{CaO}-2,01$ a 2,85\%, $\mathrm{Na}_{2} \mathrm{O}-2,44$ a $2,80 \%, \mathrm{~K}_{2} \mathrm{O}-3,70$ a $4,47 \%, \mathrm{P}_{2} \mathrm{O}_{5}-0,18$ a 0,25\%), com baixos conteúdos de $\mathrm{MnO}(0,07$ a $0,09 \%)$ e $\mathrm{MgO}(0,37$ a $0,53 \%)$. Nos diagramas binários tipo Harker para elementos maiores, as amostras mostram-se dispersas no grupo de elementos analisados (Figura 8).

As rochas que compõem o corpo de hedenberguita-hastingsita-biotita granada ortognaisse são ácidas, apresentam composição subalcalina no diagrama de classificação $\mathrm{Na}_{2} \mathrm{O}+\mathrm{K}_{2} \mathrm{O}$ vs $\mathrm{SiO}_{2}$ (Figura 9A), e cálcio-alcalina no diagrama $\mathrm{Na}_{2} \mathrm{O}+\mathrm{K}_{2} \mathrm{O}-\mathrm{Ca}$ vs $\mathrm{SiO}_{2}$ (Figura 9B), com razão molecular $\mathrm{A} / \mathrm{CNK}$ próxima de 1,0 $(0,93$ a 1,13), mostrando caráter meta-luminoso e peraluminoso (Figura 9C). De acordo com o diagrama discriminante R1 vs R2, as rochas são classificadas no limite dos campos do granodiorito e granito (Figura 9D).

O padrão de distribuição dos elementos incompatíveis normalizado pelo manto primitivo de Sun \& McDonough (1989), indica que as amostras são enriquecidas em $\mathrm{Cs}, \mathrm{Rb}, \mathrm{Ba}, \mathrm{K}, \mathrm{Zr}$ e Hf em relação a Th, U, Ta, Nb, Sr, P, Ti, Y e elementos terras raras pesados (ETRP), com discretas a fortes anomalias negativas de Th, U, Ta, Nb, Sr, P e Ti (Figura 10A).

O conteúdo total de ETR é baixo, variando de 124,73 a 223,36 ppm, com predomínio de valores em torno de $145 \mathrm{ppm}$. Os elementos terras raras leves (ETRL), normalizados pelo manto primitivo (Sun \& McDonough, 1989), apresentam concentrações entre 10,06 e 55,90 vezes acima deste, enquanto os ETRP mostram concentrações entre 4,05 a 14,41 vezes acima (Figura 10B).

O padrão de distribuição de ETR das amostras analisadas apresenta enriquecimento em ETRL em relação à ETRP (razões $\mathrm{La}_{N} / \mathrm{Eu}_{\mathrm{N}}=2,92 \mathrm{a}$ $4,14, \mathrm{Gd}_{\mathrm{N}} / \mathrm{Lu}_{\mathrm{N}}=1,85-2,30, \mathrm{La}_{\mathrm{N}} / \mathrm{Lu}_{\mathrm{N}}=7,21 \mathrm{a}$ 10,81), exibindo fracas anomalias positivas e negativas de európio ( $\mathrm{Eu}^{*}=0,93$ a 1,22).

Uma amostra (amostra P-5Cf) apresenta maiores conteúdos de ETR, um enriquecimento mais acentuado de ETRL em relação a ETRP (razões $\mathrm{La}_{N} / \mathrm{Eu}_{\mathrm{N}}=5,56, \mathrm{Gd}_{N} / \mathrm{Lu}_{\mathrm{N}}=2,13$, $\left.\mathrm{La}_{\mathrm{N}} / \mathrm{Lu}_{\mathrm{N}}=8,27\right)$ e anomalia negativa de európio mais pronunciada $\left(\mathrm{Eu}^{*}=0,56\right)$. Estas variações composicionais em relação aos ETR e Eu*, descrita nesta amostra, que exibe domínios mais deformados, provavelmente estão relacionadas às variações petrográficas resultantes de 
transformações metamórficas, como recristalização de fases minerais preexistentes, consumo de fases minerais anteriores e formação de novas fases minerais.

Nos diagramas discriminantes de ambientes geotectônicos de Pearce et al. (1984), Harris et al. (1986) e De La Roche et al. (1980), as rochas exibem composição química semelhante à de rochas geradas em arcos magmáticos (Figuras 11A, B, C, D, E, F).

Tabela 1 - Elementos maiores (\%), menores e traços (ppm) e elementos terras raras (ppm) de amostras do hedenberguita-hastingsita-biotita-granada ortognaisse.

\begin{tabular}{|c|c|c|c|c|c|c|c|c|}
\hline Elementos & P-5 & P-5Cf & P-5A & P-6A & P-7B & P-9A & P-13 & $* \mathbf{M P}$ \\
\hline $\mathrm{SiO}_{2}$ & 68,94 & 68,35 & 68,62 & 67,94 & 67,95 & 70,13 & 68,88 & \\
\hline $\mathrm{TiO}_{2}$ & 0,61 & 0,82 & 0,67 & 0,67 & 0,69 & 0,58 & 0,65 & 1300 \\
\hline $\mathrm{Al}_{2} \mathrm{O}_{3}$ & 13,81 & 12,63 & 13,39 & 13,81 & 13,76 & 13,23 & 13,07 & \\
\hline $\mathrm{Fe}_{2} \mathrm{O}_{3} \mathrm{~T}$ & 6,19 & 7,77 & 7,19 & 6,98 & 6,96 & 5,66 & 7,26 & \\
\hline $\mathrm{MnO}$ & 0,08 & 0,09 & 0,09 & 0,08 & 0,09 & 0,07 & 0,08 & \\
\hline MgO & 0,41 & 0,53 & 0,46 & 0,39 & 0,42 & 0,37 & 0,42 & \\
\hline $\mathrm{CaO}$ & 2,49 & 2,85 & 2,71 & 2,01 & 2,63 & 2,16 & 2,22 & \\
\hline $\mathrm{Na}_{2} \mathrm{O}$ & 2,78 & 2,64 & 2,78 & 2,44 & 2,80 & 2,71 & 2,71 & \\
\hline $\mathrm{K}_{2} \mathrm{O}$ & 4,29 & 3,70 & 3,82 & 4,09 & 3,83 & 4,47 & 4,21 & 250 \\
\hline $\mathrm{P}_{2} \mathrm{O}_{5}$ & 0,18 & 0,25 & 0,20 & 0,19 & 0,21 & 0,17 & 0,20 & 95 \\
\hline Total & 99,68 & 99,73 & 99,64 & 99,64 & 99,61 & 99,65 & 99,6 & \\
\hline $\mathrm{Rb}$ & 87,2 & 97,5 & 90,7 & 100,1 & 85,4 & 99,6 & 101,3 & 0,635 \\
\hline Cs & 1,2 & 1,8 & 0,9 & 1,4 & 1 & 0,6 & 1,1 & 0,0079 \\
\hline $\mathrm{Sr}$ & 263,2 & 236,2 & 269,9 & 247,8 & 280,4 & 258,8 & 257,5 & 7,26 \\
\hline $\mathrm{Ba}$ & 1795 & 1277 & 1862 & 1964 & 1990 & 1962 & 2216 & 6,989 \\
\hline $\mathrm{Y}$ & 15,5 & 30 & 21,5 & 29,3 & 19 & 19,8 & 22,2 & 4,55 \\
\hline $\mathrm{Zr}$ & 447,1 & 435,9 & 670,4 & 613,9 & 737,8 & 521,7 & 626,1 & 11,2 \\
\hline $\mathrm{Hf}$ & 12,1 & 11,8 & 15,9 & 14,4 & 17,6 & 12,6 & 14,8 & 0,309 \\
\hline $\mathrm{Nb}$ & 11,9 & 13,8 & 15,1 & 15,3 & 16,6 & 12,9 & 15,5 & 0,713 \\
\hline $\mathrm{Ta}$ & 0,6 & 0,8 & 0,9 & 0,8 & 0,8 & 0,7 & 1 & 0,041 \\
\hline $\mathrm{Pb}$ & 1,7 & 1,9 & 2 & 2,8 & 2,7 & 1,6 & 1,8 & 0,071 \\
\hline Th & 1,5 & 4,8 & 1,5 & 1,4 & 1,1 & 0,9 & 0,9 & 0,085 \\
\hline $\mathrm{U}$ & 0,6 & 0,9 & 0,7 & 0,7 & 0,6 & 0,5 & 0,7 & 0,21 \\
\hline $\mathrm{La}$ & 27,5 & 38,4 & 31,8 & 31,9 & 24,1 & 30,1 & 29,1 & 0,687 \\
\hline $\mathrm{Ce}$ & 59 & 90 & 55,2 & 54,5 & 45,4 & 57,1 & 53,9 & 1,775 \\
\hline $\operatorname{Pr}$ & 6,92 & 11,45 & 7,42 & 7,72 & 5,94 & 7,17 & 7,36 & 0,276 \\
\hline $\mathrm{Nd}$ & 26,8 & 47,1 & 29,7 & 33,8 & 27 & 29,7 & 32,7 & 1,354 \\
\hline $\mathrm{Sm}$ & 4,85 & 9,68 & 5,9 & 6,31 & 5,36 & 5,73 & 6,48 & 0,444 \\
\hline $\mathrm{Eu}$ & 1,95 & 1,69 & 1,88 & 2,15 & 2,02 & 1,89 & 1,92 & 0,168 \\
\hline $\mathrm{Gd}$ & 4,87 & 8,59 & 5,5 & 6,81 & 5,47 & 5,56 & 5,9 & 0,596 \\
\hline $\mathrm{Tb}$ & 0,65 & 1,17 & 0,76 & 0,94 & 0,68 & 0,76 & 0,8 & 0,108 \\
\hline Dy & 3,51 & 6,46 & 4,05 & 5,04 & 3,42 & 3,96 & 4,26 & 0,737 \\
\hline Ho & 0,64 & 1,22 & 0,79 & 0,99 & 0,68 & 0,72 & 0,81 & 0,164 \\
\hline Er & 1,84 & 3,48 & 2,23 & 2,71 & 1,92 & 2,12 & 2,39 & 0,48 \\
\hline $\mathrm{Tm}$ & 0,27 & 0,49 & 0,31 & 0,39 & 0,28 & 0,29 & 0,34 & 0,074 \\
\hline $\mathrm{Yb}$ & 1,85 & 3,13 & 2,2 & 2,49 & 2,1 & 1,97 & 2,31 & 0,493 \\
\hline $\mathrm{Lu}$ & 0,32 & 0,5 & 0,37 & 0,43 & 0,36 & 0,3 & 0,38 & 0,074 \\
\hline $\mathrm{La}_{\mathrm{N}} / \mathrm{Eu}_{\mathrm{N}}$ & 3,45 & 5,56 & 4,14 & 3,63 & 2,92 & 3,89 & 3,71 & 1 \\
\hline $\mathrm{Gd}_{\mathrm{N}} / \mathrm{Lu}_{\mathrm{N}}$ & 1,89 & 2,13 & 1,85 & 1,97 & 1,89 & 2,30 & 1,93 & 1 \\
\hline $\mathrm{La}_{N} / \mathrm{Lu}_{\mathrm{N}}$ & 9,26 & 8,27 & 9,26 & 7,99 & 7,21 & 10,81 & 8,25 & 1 \\
\hline Eu* & 1,22 & 0,56 & 0,99 & 1,00 & 1,13 & 1,01 & 0,93 & 1 \\
\hline
\end{tabular}

\section{Termobarometria}

A partir dos resultados de química mineral, foram realizados cálculos termobarométricos por meio do software THERMOCALC 3.26, modo Average P-T (Powell \& Holland, 1994). A assembleia mineral utilizada para o cálculo e os resultados das condições de pressão e temperatura são apresentados na tabela 2. Para os cálculos, utilizou-se atividade de $\mathrm{CO}_{2}\left(\mathrm{a}_{\mathrm{CO} 2}\right)$ igual a 0,7 . 

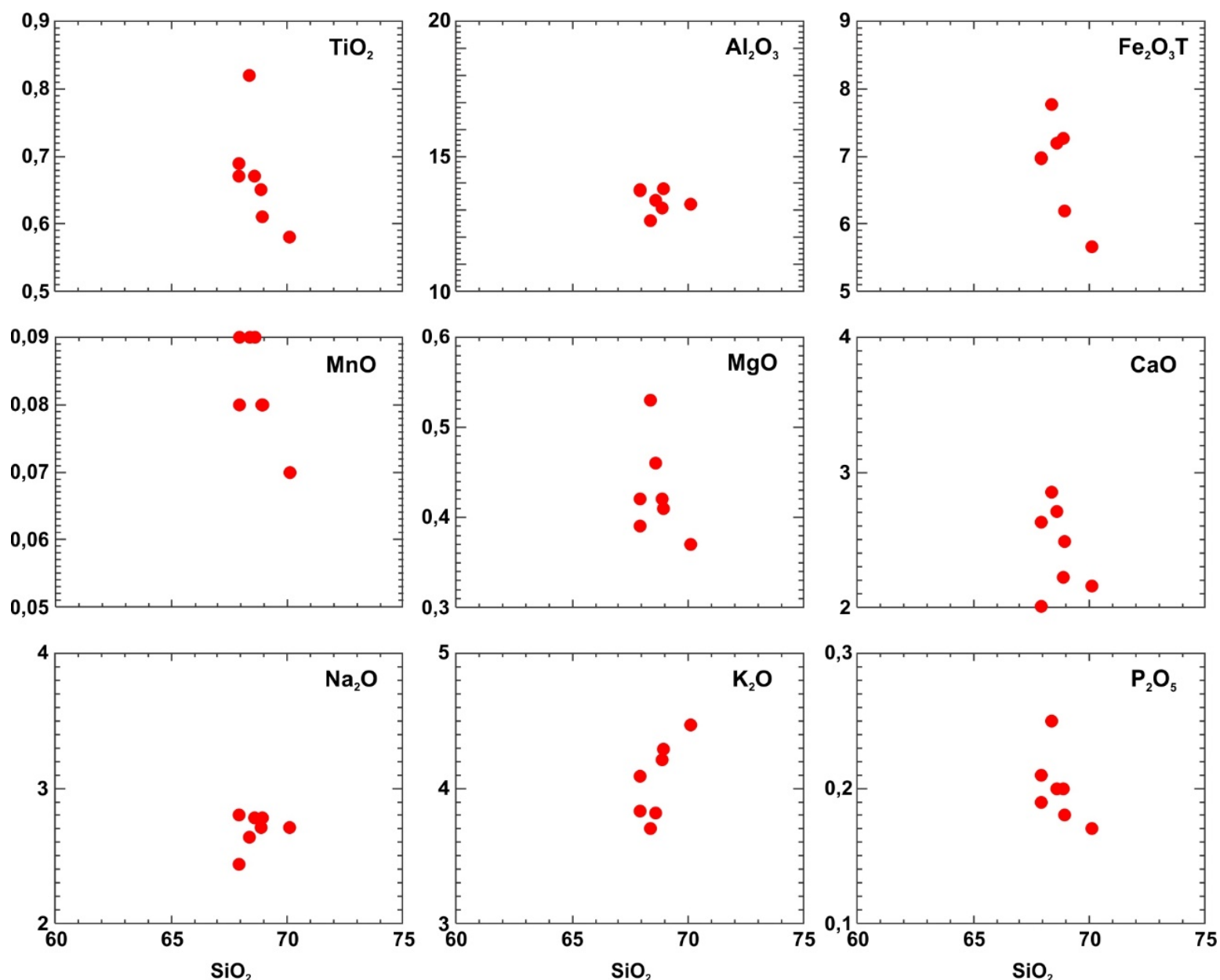

Figura 8 - Padrão de distribuição dos diagramas binários $\mathrm{TiO}_{2}, \mathrm{Al}_{2} \mathrm{O}_{3}, \mathrm{Fe}_{2} \mathrm{O}_{3} \mathrm{~T}, \mathrm{MgO}, \mathrm{CaO}, \mathrm{Na}_{2} \mathrm{O}, \mathrm{K}_{2} \mathrm{O}$ e $\mathrm{P}_{2} \mathrm{O}_{3}$ vs $\mathrm{SiO}_{2}$.

A)

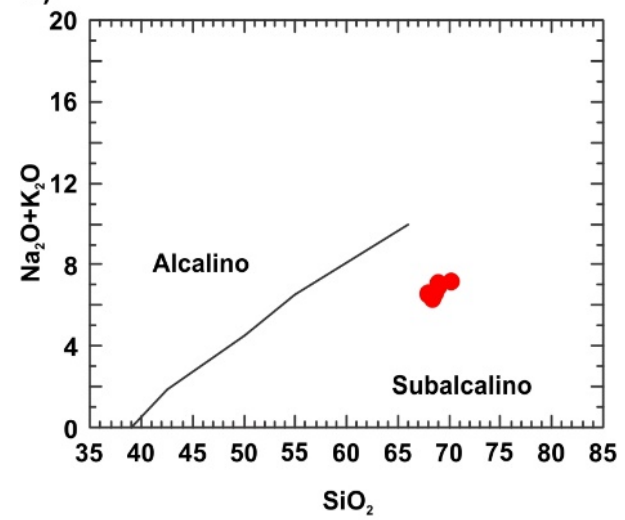

C)

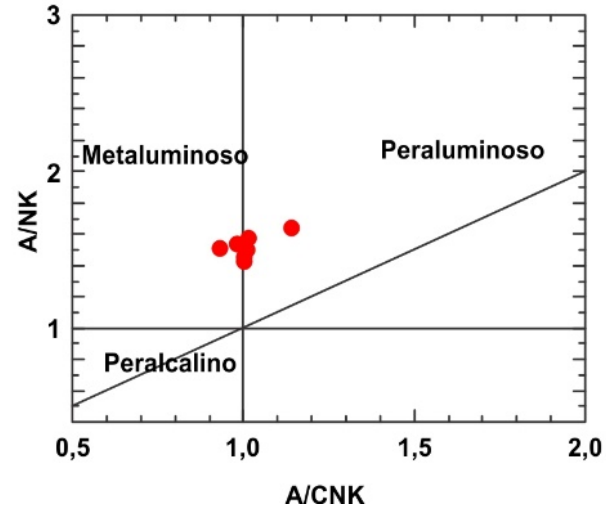

B)

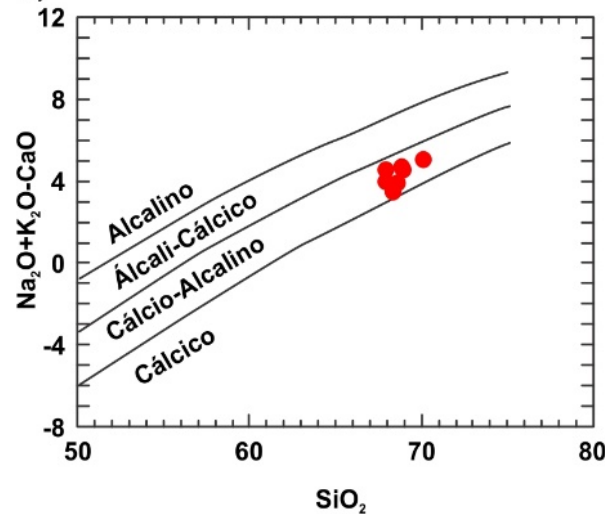

D)

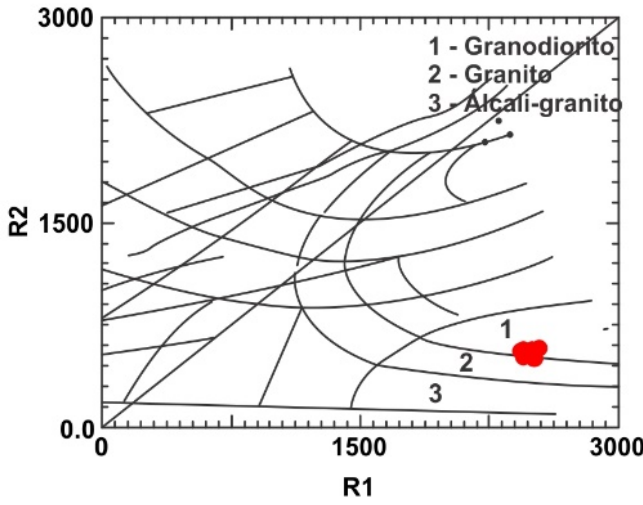

Figura 9 - Gráficos de classificação geoquímica. A) Gráfico de classificação $\mathrm{Na}_{2} \mathrm{O}+\mathrm{K}_{2} \mathrm{O}$ vs $\mathrm{SiO}_{2}$ (Irvine \& Baragar, 1971); B) $\mathrm{Na}_{2} \mathrm{O}+\mathrm{K}_{2} \mathrm{O}-\mathrm{CaO}$ vs $\mathrm{SiO}_{2}$ (Frost et al., 2001); C) Gráfico A/NK-A/CNK (Shand, 1943); D) Diagrama R1 [4Si11(Na+K)-2(Fe+Ti)] vs R2 [Al+2Mg+6Ca] de classificação para rochas plutônicas (De La Roche et al., 1980). 
A)

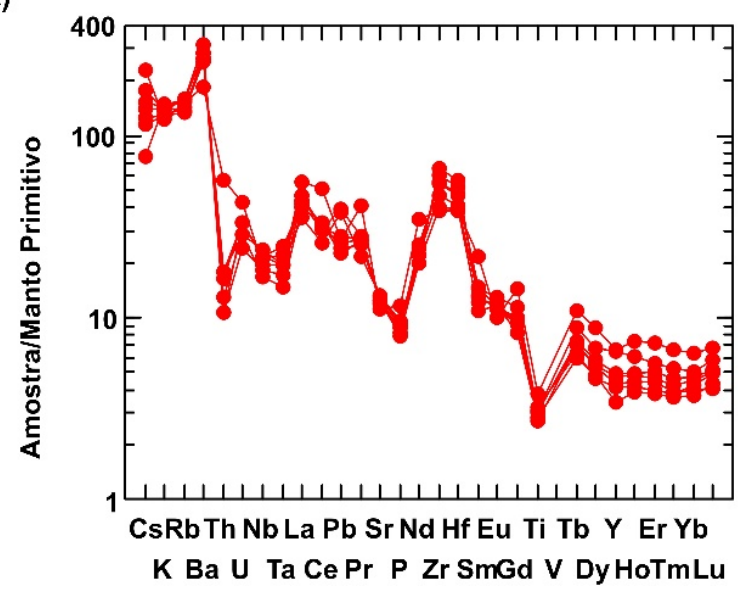

B)

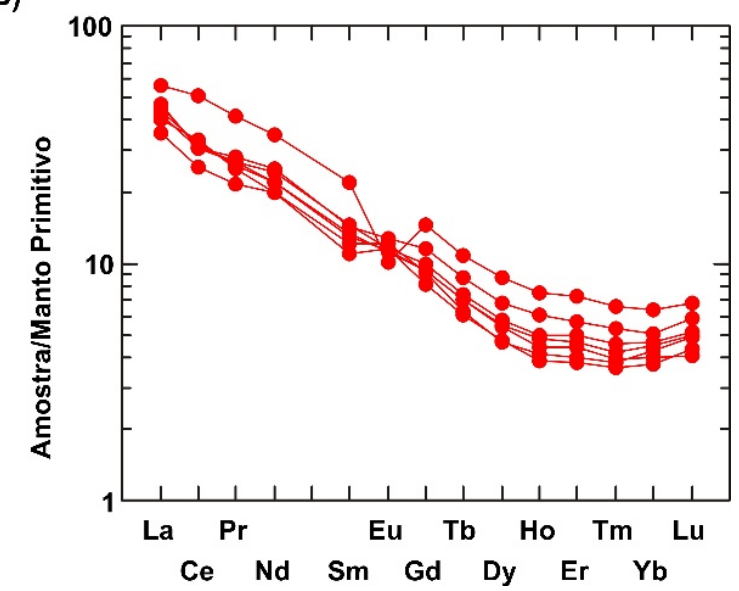

Figura 10 -Diagramas de distribuição de elementos incompatíveis e ETR. A) Diagrama de distribuição para elementos menores, traços e ETR (normalizados pelo Manto Primitivo, Sun \& McDonough, 1989); B) Diagrama de distribuição dos elementos terras raras (normalizados pelo Manto Primitivo, Sun \& McDonough, 1989).

A)

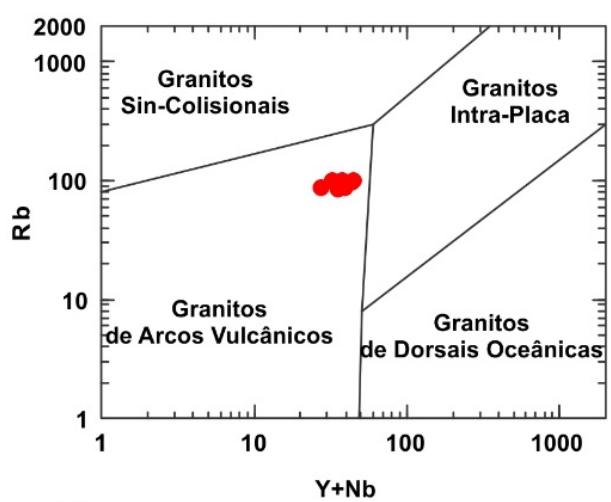

c)

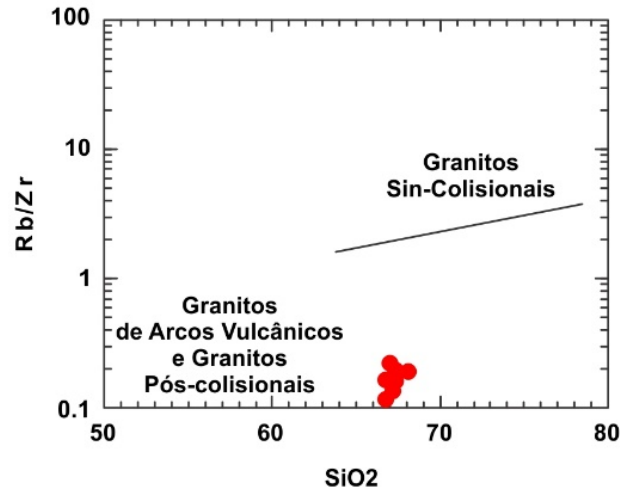

E)

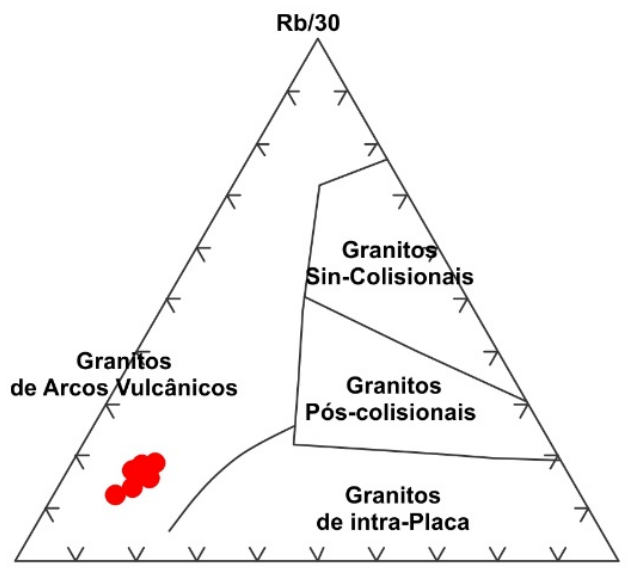

B)

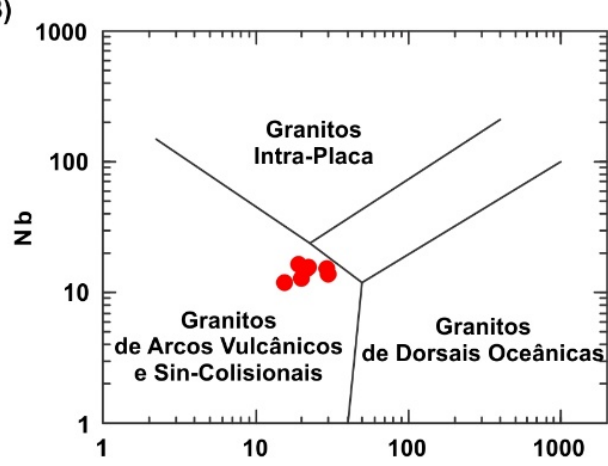

D)

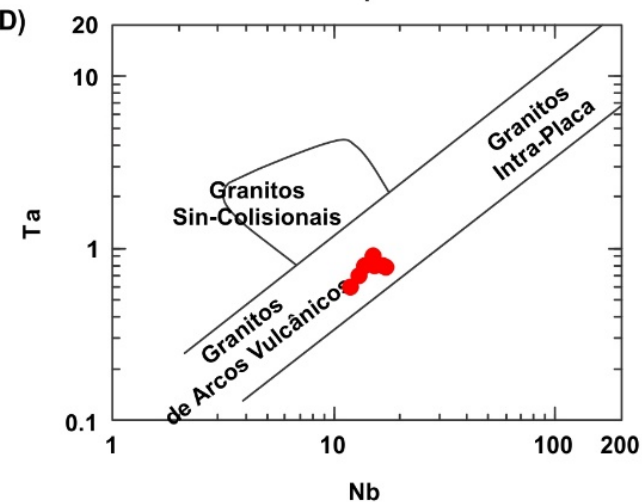

F)

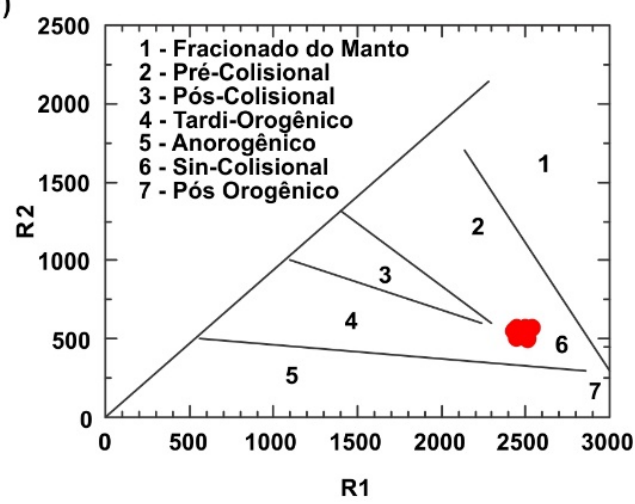

Hf

$\mathrm{Ta}^{*} 3$

Figura 11 - Gráficos discriminantes de ambientes tectônicos. A) Gráfico Rb vs Y+Nb (Pearce et al., 1984); B) Gráfico $\mathrm{Nb}$ vsY (Pearce et al., 1984); C) Gráfico Rb/Zr vs SiO (Harris et al., 1986); D) Gráfico Ta vs Nb (Harris et al., 1986); E) Gráfico Rb/30 vs Hf vs Ta*3 (Harris et al., 1986); F) Gráfico R1 [4Si-11(Na+K)-2(Fe+Ti)] vs R2 [Al+2Mg+6Ca] (De La Roche et al., 1980). 
Tabela 2 - Condições $P$-T calculadas pelo software THERMOCALC (Average P-T).

\begin{tabular}{c|c}
\hline Assembleia Mineral & P (Kbar)/T ( $\left.{ }^{\circ} \mathbf{C}\right)$ \\
\hline $\mathrm{Pl}+\mathrm{Or}+\mathrm{Qtz}+\mathrm{Amp}+\mathrm{Bt}+\mathrm{Cpx}$ & $7,0 \pm 0,5 / 666 \pm 29$ \\
\hline $\mathrm{Pl}+\mathrm{Or}+\mathrm{Qtz}+\mathrm{Amp}+\mathrm{Bt}+\mathrm{Cpx}$ & $8,8 \pm 0,7$ / 635 \pm 34 \\
\hline $\mathrm{Pl}+\mathrm{Or}+\mathrm{Qtz}+\mathrm{Amp}+\mathrm{Bt}+\mathrm{Cpx}$ & $11,2 \pm 0,7 / 698 \pm 29$ \\
\hline $\mathrm{Pl}+\mathrm{Or}+\mathrm{Qtz}+\mathrm{Amp}+\mathrm{Bt}+\mathrm{Cpx}$ & $9,3 \pm 0,7 / 619 \pm 33$ \\
\hline $\mathrm{Pl}+\mathrm{Or}+\mathrm{Qtz}+\mathrm{Amp}+\mathrm{Bt}$ & $10,6 \pm 0,7 / 786 \pm 45$ \\
\hline $\mathrm{Pl}+\mathrm{Or}+\mathrm{Qtz}+\mathrm{Amp}+\mathrm{Bt}$ & $10,0 \pm 1,1 / 706 \pm 68$ \\
\hline $\mathrm{Pl}+\mathrm{Or}+\mathrm{Qtz}+\mathrm{Amp}+\mathrm{Bt}$ & $10,1 \pm 0,7 / 771 \pm 49$ \\
\hline
\end{tabular}

As condições de pressão e temperatura calculadas com assembleia mineral constituída por andesina + almandina + quartzo + ortoclásio + siderofilita + hastingsita/ferro-pargasita + hedenberguita variam de 7,0 $\pm 0,5$ a 11,2 $\pm 0,7$ kbar e $619 \pm 33$ a $698 \pm 29^{\circ} \mathrm{C}$ (Figura 12, Tabela 2). Nas porções mais deformadas, nas quais a hedenberguita não está presente na associação mineral do ortognaisse (andesina/oligoclásio + almandina + quartzo + ortoclásio + siderofilita + hastingsita/ferro-pargasita), as condições variam de $10,0 \pm 1,1$ a $10,6 \pm 0,7$ kbar e $706 \pm 68$ a 786 $\pm 45^{\circ} \mathrm{C}$ (Figura 12, Tabela 2). Quando o anfibólio e a biotita são excluídos da associação mineral, não é possível quantificar as condições de pressão e temperatura, sugerindo que uma ou mais fases estão em desequilíbrio.

\section{Idade Modelo}

Uma amostra do corpo de hedenberguitahastingsita-biotita-granada ortognaisse foi selecionada para análise isotópica $\mathrm{Sm} / \mathrm{Nd}$. A idade modelo $\mathrm{T}_{\mathrm{DM}(\mathrm{Nd})}$ foi calculada segundo o modelo de De Paolo (1981). Os resultados da análise são apresentados na tabela 3.

As razões isotópicas ${ }^{147} \mathrm{Sm} /{ }^{144} \mathrm{Nd}$ e ${ }^{143} \mathrm{Nd} /{ }^{147} \mathrm{Nd}$ obtidas para amostra apresentam $\mathrm{T}_{\mathrm{DM}(\mathrm{Nd})}$ de 2,2 Ga, $\varepsilon_{\text {Nd }}$ de $-21,7$ (Figura 13), e razões ${ }^{147} \mathrm{Sm} /{ }^{144} \mathrm{Nd}$ de 0,12 e de ${ }^{143} \mathrm{Nd} /{ }^{147} \mathrm{Nd}$ de 0,511526 . O valor de $\varepsilon_{\mathrm{Nd}}$ sugere que a rocha teve elevado tempo de residência crustal.

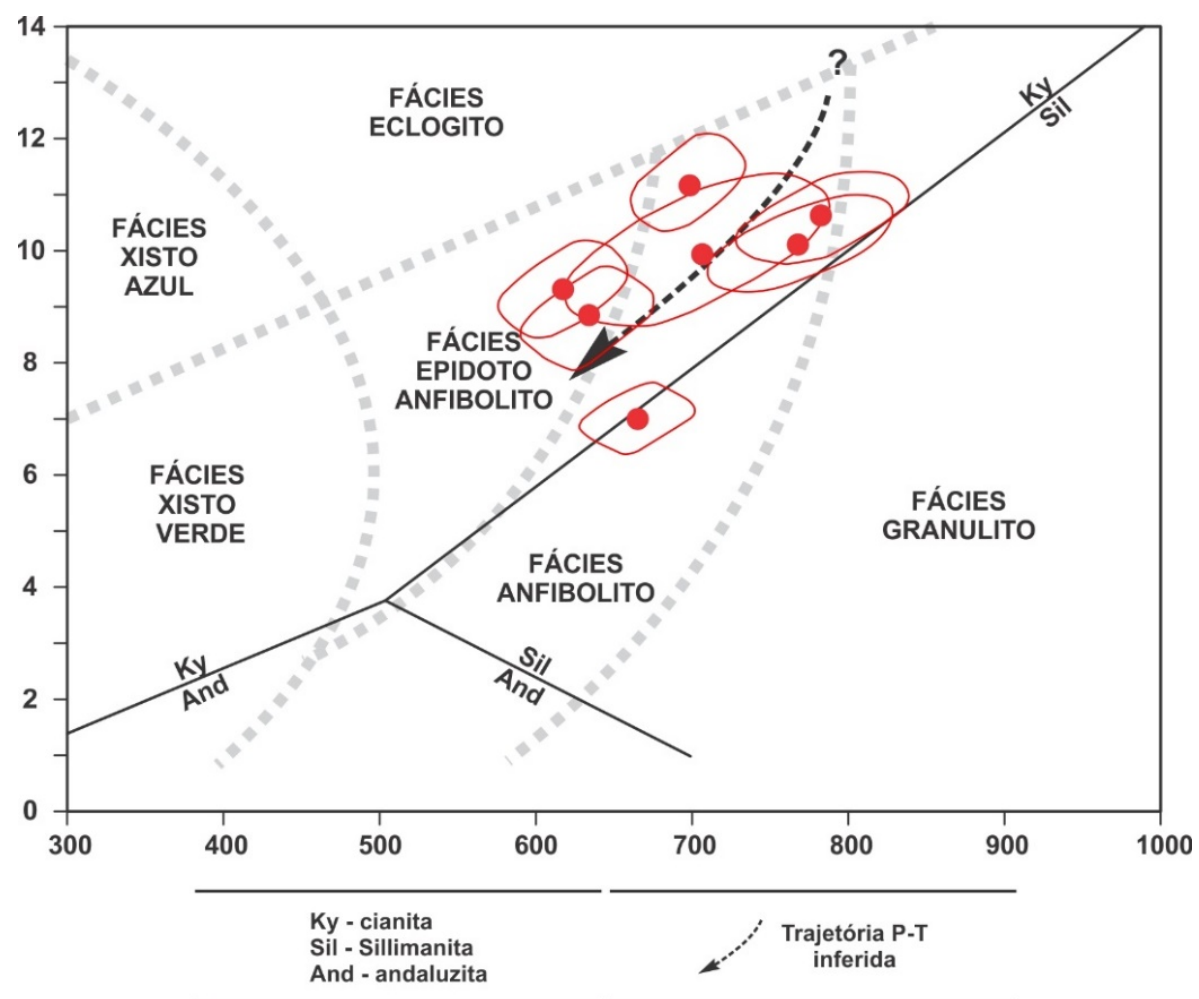

Figura 12 - Diagrama $P$-T mostrando as condições de pressão e temperatura calculadas pelo software THERMOCALC (Average P-T). Diagrama de fácies metamórfica extraído de Spear (1993).

Tabela 3 - Análise isotópica Sm/Nd.

\begin{tabular}{c|c|c|c|c|c|c}
\hline Amostra & Sm $\mathbf{( p p m ) ~}$ & $\mathbf{N d}(\mathbf{p p m})$ & ${ }^{\mathbf{1 4 7}} \mathbf{S m} /{ }^{\mathbf{1 4 4}} \mathbf{N d}$ & ${ }^{\mathbf{1 4 3}} \mathbf{N d} /{ }^{\mathbf{1 4 4}} \mathbf{N d}$ & $\boldsymbol{\varepsilon}_{(\mathbf{N d})}$ & $\mathbf{T}_{\mathbf{D M}(\mathbf{N d})}(\mathbf{G a})$ \\
\hline $\begin{array}{c}\text { P-5A - hedenberguita-hastingsita- } \\
\text { biotita-granada ortognaisse }\end{array}$ & 5,9 & 29,7 & 0,12 & 0,511526 & $-21,7$ & 2,2 \\
\hline
\end{tabular}



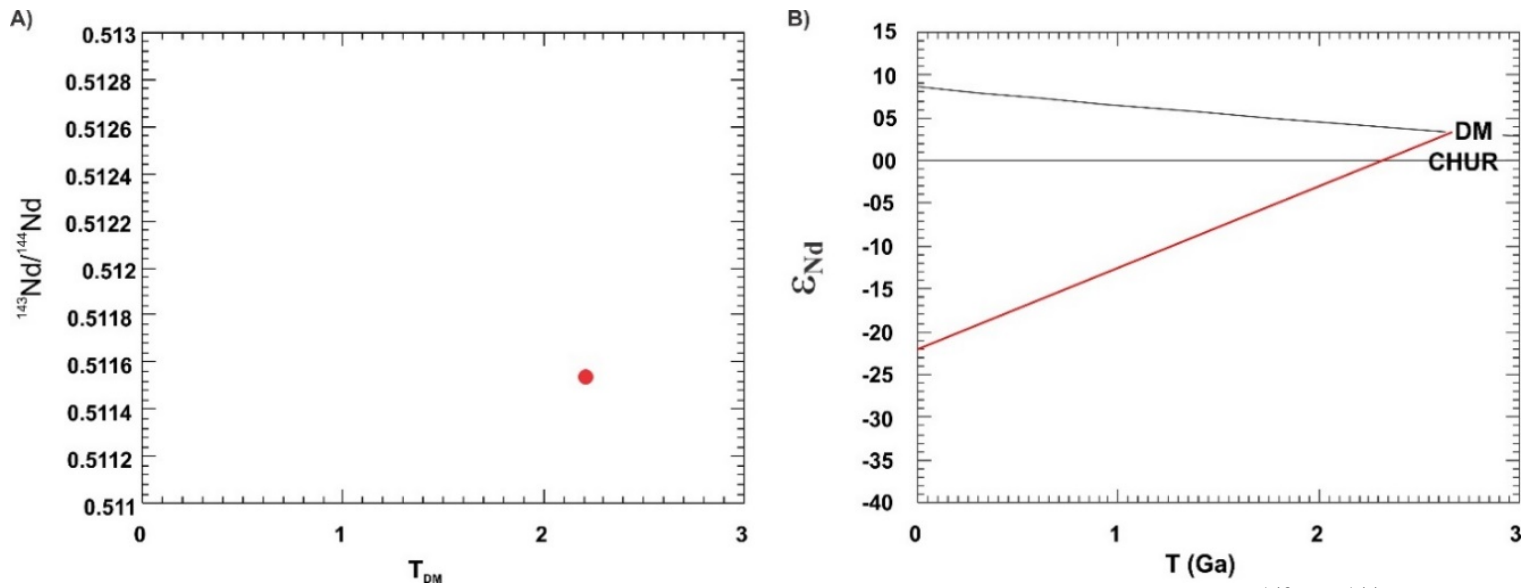

Figura 13 - Resultados da análise isotópica Sm/Nd. A) Diagrama mostrando variação da razão ${ }^{143} \mathrm{Nd} /{ }^{144} \mathrm{Nd}$ versus idade modelo $\left(\mathrm{T}_{\mathrm{DM}} \mathrm{Nd}\right)$; B) Diagrama de evolução de $\varepsilon_{\mathrm{Nd}}$ com o tempo mostrando valor fortemente negativo para a amostra analisada (linha vermelha).

\section{Metamorfismo e Evolução}

As feições mineralógicas e texturais, assim como a associação mineral presente no ortognaisse (plagioclásio, ortoclásio, quartzo, granada, clinopiroxênio rico em $\mathrm{Ca}$ e $\mathrm{Fe}$ ), indicam auge metamórfico em condições de fácies granulito, com temperaturas mínimas da ordem de $800^{\circ} \mathrm{C}$, no campo de estabilidade da cianita, acima da isógrada do ortoclásio.

Em todas as amostras do corpo de ortognaisse, tanto nos termos mais isotrópicos como nos mais deformados, observam-se reações retrometamórficas em consequência do reequilíbrio metamórfico regional, que ocorreram com grau variado nas rochas, indicando que o processo foi penetrativo, embora com intensidade variada. As reações retrógradas indicam reequilíbrio das associações minerais em fácies anfibolito superior a médio e são marcadas principalmente por substituição de clinopiroxênio por anfibólio; passagem de ortoclásio para microclínio; passagem de anfibólio para biotita e em muitos casos com geração de titanita e opacos; cristais de granada com bordas de anfibólio e biotita; além da presença de mirmequitas.

As características químicas da granada, biotita e anfibólio analisados, corroboram condições de metamorfismo de alto grau. As análises de química mineral da granada mostram perfis composicionais quase retos e com sutis variações composicionais em direção às bordas dos cristais, características comuns em condições de alto grau metamórfico, uma vez que em condições de altas temperaturas (acima de $700^{\circ} \mathrm{C}$ ), ocorre redução do zoneamento composicional, representando a homogeneização da composição, seguida de pouca modificação durante o resfriamento, marcado pelas sutis variações composicionais em direção às bordas dos cristais (Tracy et al., 1976; Woodsworth, 1977; Yardley, 1977; Spear, 1993; Carlson \& Schwarze, 1997; Cooke et al., 2000). Os altos conteúdos de $\mathrm{X}_{\mathrm{Mg}}, \mathrm{Al}^{\mathrm{IV}}$, Ti e baixos teores de $\mathrm{Al}^{\mathrm{VI}}$ na composição da biotita, indicam características típicas de alto grau metamórfico (Guidotti, 1984), assim como os teores relativamente altos de $\mathrm{Na}_{\mathrm{A}}$ e $\mathrm{K}_{\mathrm{A}}$ e de $\mathrm{Al}^{\mathrm{IV}}, \mathrm{Al}^{\mathrm{VI}} \mathrm{e}$ Ti na composição do anfibólio, que também sugerem condições de temperatura mais elevadas (Zakrutkin \& Grigorenko, 1967; Kotyuk \& Sobolev, 1969; Robinson et al., 1982; Deer et al., 1997).

As condições de pressão e temperatura calculadas na termobarometria para a associação mineral com hedenberguita são inferiores ao esperado, considerando as características mineralógicas, texturais e químicas das amostras analisadas, além das rochas encaixantes ao ortognaisse e o contexto geológico regional. As menores condições de pressão e temperatura calculadas e a pouca homogeneidade nos resultados são provavelmente explicadas devido ao desequilíbrio de uma ou mais fases minerais com o sistema químico calculado. Quando a hedenberguita é excluída da assembleia mineral para os cálculos termobarométricos, as condições $P-T$ são mais realistas e coerentes com as condições de pressão e temperatura do reequilíbrio metamórfico regional estimado para a área de estudo (condições de $P$ - $T$ entre 770 a $700^{\circ} \mathrm{C}$ e 13,5 a 10,0 kbar) (Zanardo, 1992, 2003; Del Lama, 1993; Del Lama et al., 1994; Leme, 2016, 2019; Leme et al., 2019).

Os dados mineralógicos, petrográficos e químicos em congruência com os dados de geotermobarometria e idade modelo sugerem um protólito ígneo para o litotipo estudado, formado 
a partir de fusão de rochas paleoproterozoicas, cuja mineralogia era constituída provavelmente por ortoclásio, andesina, granada, hedenberguita e quartzo, que esteve em equilíbrio com as condições do auge metamórfico da área de estudo (fácies granulito de alta pressão).

Posterior ao auge metamórfico, durante a implantação das zonas de cisalhamento, o litotipo foi afetado por deformação diferencial progressiva em condições ainda dúcteis, em diferentes graus de intensidade, que catalisou transformações minerais retrogressivas, dando origem a mineralogia hidratada (anfibólio e biotita) e apagando as feições reliquiares nas porções mais deformadas. As condições termobarométricas estimadas neste estágio registram condições $P$ - $T$ em torno de 11,0-10,5 kbar e 750$700^{\circ} \mathrm{C}$, e são condizentes com as estimadas para o reequilíbrio metamórfico regional.

Os dados obtidos neste trabalho, em concordância com as condições de pressão e temperatura do metamorfismo regional estimado para a área de estudo, sugerem trajetória metamórfica com sentido horário, compatíveis com zonas de colisão continental.

A mineralogia pouco comum, que associa clinopiroxênio rico em $\mathrm{Ca}$ e $\mathrm{Fe}$ e granada em sistemas de composição granítica/granodiorítica originada a partir de produto de fusão, foi sugerida por Patiño Douce (2005) por meio de experimentos de fusão de assembleias tonalíticas (biotita+ anfibólio + plagioclásio + quartzo) mostrando que a associação mineral pode ser formada em sistemas ígneos estáveis em temperaturas mínimas da ordem de $900^{\circ} \mathrm{C}$ e pressões acima de 15 kbar. Essas condições são congruentes com as estimadas para o auge metamórfico da porção mais meridional da faixa de rochas atribuídas ao Grupo Araxá (Zanardo, 1992, 2003; Del Lama, 1993; Del Lama et al., 1994; Zanardo et al., 2006; Leme, 2019; Leme et al., 2019).

\section{CONSIDERAÇÕES FINAIS}

O hedenberguita-hastingsita-biotita-granada ortognaisse configura um corpo lenticular, orientado segundo a direção E-W, paralelo a subparalelo à direção das zonas de cisalhamento regionais, e está inserido no contexto de rochas de alta pressão atribuídas ao Grupo Araxá. As rochas que constituem o corpo de ortognaisse apresentam estrutura isotrópica a anisotrópica, podendo exibir domínios bem mais foliados e orientados, em consequência do maior grau de deformação. Nas porções centrais do corpo, a estrutura é predominantemente isotrópica com textura granular hipidiomórfica/alotriomórfica a granoblástica, de granulação média a grossa, tendendo a termos mais anisotrópicos com textura granoblástica inequigranular de granulação média a fina nas bordas do corpo.

As análises geoquímicas mostram que são rochas de tendência cálcio-alcalina e com razão A/CNK próximo de 1,0. O padrão de distribuição dos elementos traços e ETR sugerem que o ortognaisse em estudo apresenta características geoquímicas semelhantes à de rochas geradas em arcos magmáticos.

A idade modelo $\mathrm{T}_{\mathrm{DM}(\mathrm{Nd})}$, calculada a partir de dados isotópicos $\mathrm{Sm} / \mathrm{Nd}$, indica elevado tempo de residência crustal.

As observações mineralógicas, texturais e petrológicas em consonância com os dados químicos e isotópicos sugerem um protólito ígneo de idade paleoproterozoica, constituído provavelmente por ortoclásio, andesina, granada, hedenberguita e quartzo.

A associação mineral constituída por andesina + ortoclásio + quartzo + granada + hedenberguita, observada nas porções menos deformadas do corpo de ortognaisse, sugere que esta esteve em equilíbrio com as condições de $P$ $T$ durante o auge metamórfico (fácies granulito de alta pressão). Posterior ao auge metamórfico, o ortognaisse foi afetado por deformação diferencial progressiva em condições ainda dúcteis, em diferentes graus de intensidade, que catalisou transformações minerais retrogressivas. As condições de pressão e temperatura calculadas (em torno de 11,0-10,5 kbar e 750$700^{\circ} \mathrm{C}$ ), são congruentes com o reequilíbrio metamórfico regional, e não indicam as condições do auge metamórfico. Os dados obtidos indicam trajetória metamórfica com sentido horário, compatível com zonas de colisão continental.

\section{AGRADECIMENTOS}

Os autores externam seus agradecimentos à FAPESP (processo 2013/04235-2), pelo apoio financeiro. 


\section{REFERÊNCIAS}

ALMEIDA, F.F.M. O cráton do São Francisco. Revista Brasileira de Geociências, v. 7, n. 4, p. 349-364, 1977.

ALMEIDA, F.F.M. Origem e evolução da plataforma brasileira. Boletim da Divisão de Geologia e Mineralogia. Rio de Janeiro: DNPM. n. 241, 1967. 36p.

ALMEIDA, F.F.M.; HASUI, Y.; DAVINO, A.; HARALYI, N.L.E. Informações geofísicas sobre o oeste mineiro e seu significado geotectônico. Anais da Academia Brasileira de Ciências, v. 52, n. 1, p. 49-60, 1980.

BOHLEN, S.R. On the formation of granulites. Journal of Metamorphic Geology, n. 9, p. 223-229, 1991.

BROWN, M. Metamorphic patterns in orogenic systems and the geological record. In: CAWOOD, P.A. \& KRÖNER, A. (Eds), Earth Accretionary Systems in Space and Time. Geological Society, London, Special Publications, v. 318, n. 1, p. 37-74, 2009.

BROWN, M. The contribution of metamorphic petrology to understanding lithosphere evolution and geodynamics. Geoscience Frontiers, v. 5, p. 553-569, 2014.

CAMPOS NETO, M.C. \& CABY, R. Neoproterozoic HighPressure Metamorphism and Tectonic Constraint from the Nappe System South of the São Francisco Craton, Southeast Brazil. Precambrian Research, n. 97. p. 3-26, 1999.

CAMPOS NETO, M.C. \& CABY, R. Terrane Accretion and Upward Extrusion of High-Pressure Granulites in the Neoproterozoic Nappes of Southeast Brazil: Petrologic and Structural Constraints. Tectonics, n. 19, n. 4, p. 669-687, 2000.

CAMPOS NETO, M.C.; BASEI, M.A.S.; JANASI, V.A.; MORAES, R. Orogen migration and tectonic setting of the Andrelândia Nappe system: An Ediacaran western Gondwana collage, south of São Francisco craton. Journal of South American Earth Sciences, v. 32, n. 4, p. 393-406, 2011.

CARLSON, W. \& SCHWARZE, E. Petrological significance of prograde homogenization of growth zoning in garnet: an example from the Llano Uplift. Journal of Metamorphic Geology, v. 15, n. 5, p. 631-644, 1997.

CARSWELL, D.A. \& COMPAGNONI, R. Introduction with review of the definition, distribution and geotectonic significance of ultrahigh pressure metamorphism. In: CARSWELL, D.A. \& COMPAGNONI, R. (Eds.), Ultra-high pressure metamorphism. Eötvös University Press, Budapest. European Mineralogical Union Notes Mineral, v. 5, p. 1-7, 2003.

CAVALCANTE, J.C.; CUNHA, H.C.; CHIEREGATI, L.A.; KAEFER, L.Q.; ROCHA, J.M.; DAITX, E.C.; COUTINHO, M.G.N.; YAMAMOTO, K.; DRUMOND, J.B.V.; ROSA, D.B.; RAMALHO, R. Projeto Sapucaí - Estados de São Paulo e Minas Gerais (Relatório Final de Geologia). DNPM/CPRM, Brasília, 1979, 299 p.

CHOPIN, C. Ultrahigh-pressure metamorphism: tracing continental crust into the mantle. Earth and Planetary Science Letters, v. 212, p. 1-14, 2003.

COOKE, R.A.; O'BRIEN, P.J.; CARSWELL, D.A. Garnet zoning and the identification of equilibrium mineral compositions in high-pressure-temperature granulites from the Moldanubian Zone, Austria. Journal of Metamorphic Geology, v. 18, n. 5, p. 551-569, 2000.

DE LA ROCHE, H.; LETERRIER, J.T.; GRANDCLAUDE, P.; MARCHAL, M. A classification of volcanic and plutonic rocks using R1 vs R2-diagram and major-element analyses its relationships with current nomenclature. Chemical Geology, v. 29, n. 1-4, p. 183-210, 1980.

DE PAOLO, D.J. A neodymium and strontium isotopic study of the Mesozoic calc alcaline granitic batholiths of the Sierra Nevada and Peninsular Ranges, California. Journal of Geophysical Research, v. 86, p. 10470-10488, 1981.

DEER, W.A.; HOWIE, R.A.; ZUSSMAN, J. Rock-forming minerals. Double-chain silicates - v. 2A. 2 ed. The Geological Society Publishing House, London, Inglaterra, 1997, 764 p.

DEL LAMA, E.A. Petrologia das rochas metamórficas de alto grau do Complexo Campos Gerais e correlação com as do
Complexo Varginha-Guaxupé: Estudos termobarométricos. Rio Claro, 1993. 132 p. Dissertação (Mestrado) Instituto de Geociências e Ciências Exatas, Universidade Estadual Paulista.

DEL LAMA, E.A. Terrenos granulíticos de Guaxupé: Evolução petrológica de um segmento da crosta inferior. Rio Claro, 1998. 188 p. Tese (Doutorado) - Instituto de Geociências e Ciências Exatas, Universidade Estadual Paulista.

DEL LAMA, E.A.; OLIVEIRA, M.A.F.; ZANARDO, A. Geotermobarometria em rochas do Complexo Campos Gerais ao norte da Zona de Cisalhamento Varginha. Revista Brasileira de Geociências, v. 24, n. 4, p. 1-7, 1994.

FROST, B.R.; BARNES, C.G.; COLLINS, W.J.; ARCULUS, R.J.; ELLIS, D.J.; FROST, C.D.A. Geochemical Classification for Granitic Rocks. Journal of Petrology, v. 42, n. 11, p. 20332048, 2001.

GODOY, A.M.; OLIVA, A.; MORALES, N.; ZANARDO, A. Geologia e geoquímica das rochas graníticas da Zona de Sutura Alterosa, região de São Pedro da União-MG. Revista Brasileira de Geociências, São Paulo, v. 18. n. 2, p. 417-437, 1999.

GUIDOTTI, C.V. Micas in metamorphic rocks. In: BAILEY, S.W. (Ed). Micas. Reviews in Mineralogy and Geochemistry, Mineralogical Society of America, Washington, D.C., v. 13, n. 1, p. 357-467, 1984

HARALYI, N.L.E. \& HASUI, Y. The gravimetric information and the archean-proterozoic structural framework of eastern Brazil. Revista Brasileira de Geociências, v. 12, n. 1-2-3, 1982, p. 160-166.

HARALYI, N.L.E.; HASUI, Y.; MIOTO, J.A.; HANZA, V.M.; RODRIGUES, C.R.V. Ensaio sobre a estruturação crustal do Estado de Minas Gerais com base na informação geofísica e geológica. Contribuições à Geologia e a Petrologia. Boletim Especial. Sociedade Brasileira de Geologia, 1985, p. 71-93.

HARLEY, S.L. On the occurrence and characterization of ultrahigh-temperature crustal metamorphism. In: TRELOAR, P.J. \& O’BRIEN, P.J. (Eds), What Drives Metamorphism and Metamorphic Reaction? Geological Society, London. Special Publications, v. 138, p. 81-107, 1998.

HARLEY, S.L. The origins of granulites: a metamorphic perspective. Geological Magazine, v. 126, p. 215-247, 1989.

HARRIS, N.B.W; PEARCE, J.A.; TINDLE, A.G.; Geochemical characteristics of collision-zone magmatism. Geological Society Special Publications, v. 19, n. 1, p. 67-81, 1986.

HASUI, Y. A grande colisão pré-cambriana do sudeste brasileiro e a estruturação regional. Geociências, v. 29, n. 2, p. 141-169, 2010.

IRVINE, T.N.J. \& BARAGAR, W.R.A.F. A guide to the chemical classification of the common volcanic rocks. Canadian Journal of Earth Sciences, v. 8, n. 5, p. 523-548, 1971.

KELSEY, D.E. On ultrahigh-temperature crustal metamorphism. Gondwana Research, v. 13, p. 1-29, 2008.

KOSTYUK, E.A. \& SOBOLEV, V.S. Paragenetic types of calciferous amphiboles of metamorphic rocks. Lithos, v. 2, p. 67-81, 1969.

LEAKE, B.E., WOOLLEY, A.R.; ARPS, C.E.S.; BIRCH, W.; GILBERT, M.C.; HAWTHORNE, F.C.; GRICE, J.D.; KATO, A.; KISCH, H.; KRIVOVICHEV, V.; LINTHOUT, K.; LAIRD, J.; MANDARINO, J.A.; MARESCH, W.; NICKEL, E.; ROCK, N.M.S., SCHUMACHER, J.C; SMITH, D.C.; STEPHENSON, N.C.N; UNGARETTI, E.J.W.; YOUZHI, G. Nomenclature of amphiboles: report of the subcommittee on amphiboles of the international mineralogical association, commission on new minerals and mineral names. The Canadian Mineralogist, v. 35, p. 219-246, 1997.

LEME, T.G. Petrografia e geoquímica da ocorrência de (clinopiroxênio)-hastingsita-biotita-granada ortognaisse na região de Santa Cruz do Prata-MG. Rio Claro, 2016, 87 p. Trabalho de Conclusão de Curso - Instituto de Geociências e Ciências Exatas, Universidade Estadual Paulista.

São Paulo, UNESP, Geociências, v. 39, n. 3, p. 505 - 608, 2020 
LEME, T.G. Geotermobarometria das rochas do Grupo Araxá e do Complexo Guaxupé na região de Guaxupé Nova Resende, MG. Rio Claro, 2019, 175 p. Dissertação (Mestrado) - Instituto de Geociências e Ciências Exatas, Universidade Estadual Paulista.

LEME, T.G.; NAVARRO, G.R.B.; ZANARDO, A.; MONTIBELLER, C.C. Petrografia, química mineral e geotermobarometria de retroeclogito no Grupo Araxá na região da Zona de Cisalhamento Varginha, sudoeste de Minas Gerais. Geociências, v. 38, n. 2, p. 297-313, 2019.

LIMA, F.G. Evolução petrogenética das rochas máficas/ultramáficas na área ao sul do Cráton São Francisco, entre as cidades de Fortaleza de Minas e JacuíMG. 2014. 104p. Dissertação (Mestrado) - - Instituto de Geociências e Ciências Exatas, Universidade Estadual Paulista.

LIOU, J.G.; ERNST, W.G.; ZHANG, R.Y.; TSUJIMORI, T.; JAHN, J.G. Ultrahigh-pressure minerals and metamorphic terranes - the view from China. Journal of Asian Earth Sciences, v. 35, p. 199-231, 2009.

LIOU, J.G.; TSUJIMORI, T.; YANG, J.S.; ZHANG, R.Y.; ERNST, W.G. Recycling of crustal materials through study of ultrahigh-pressure minerals in collisional orogens, ophiolites, and mantle xenoliths: a review. Journal of Asian Earth Sciences, v. 96, p. 386-420, 2014.

MALAGUTTI FILHO, W.; EBERT, H.D.; HASUI, Y.; HARALYI, N.L.E.; STURARO, J.R. Gravimetria e compartimentação crustal do sul de Minas Gerais. Geociências, v. 15, n. 1, p. 199-217, 1996.

MORALES, N. Evolução tectônica do cinturão de cisalhamento Campo do Meio na sua porção ocidental. Rio Claro, 1993. 2v. Tese (Doutorado) - Instituto de Geociências e Ciências Exatas, Universidade Estadual Paulista.

MORIMOTO, N. Nomenclature of pyroxenes. Mineralogy and Petrology, v. 39, n. 1, p. 55-76, 1988.

O'BRIEN, P.J. \& RÖTZLER, J. High-pressure granulites: formation, recovery of peak conditions and implications for tectonics. Journal of Metamorphic Geology, v. 21, n. 1, p. 320, 2003.

PATIÑO DOUCE, A.E. Vapor-absent melting of tonalite at 1532 kbar. Journal of Petrology, v. 46, n. 2, p. 275-290, 2005.

PAULY, J.; MARSCHALL, H.R.; MEYER, H.P.; CHATTERJEE, N.; MONTELEONE, B. Prolonged Ediacaran-Cambrian metamorphic history and short-lived high-pressure granulite-facies metamorphism in the HU Sverdrupfjella, Dronning Maud Land (East Antarctica): evidence for continental collision during Gondwana assembly. Journal of Petrology, v. 57, n. 1, p. 185-228, 2016.

PEARCE, J.A.; HARRIS, N.B.W; TINDLE, A.G. Trace element discrimination diagrams for the tectonic interpretation of granitic rocks. Journal of Petrology, v. 25, n. 4, p. 956-983, 1984.

POWELL, R. \& HOLLAND, T.J.B. Optimal geothermometry and geobarometry. American Mineralogist, v. 79, p. 120-133, 1994.

RICHARD, L.R. Mineralogical and Petrological Data Processing System. MINPET for Windows. Version 2.02. Copyright 1988-1995, 1995.

ROBINSON, P.; SPEAR, F.S.; SCHUMACHER, J.C.; LAIRD, J.; KLEIN, C.; EVANS, B.W.; DOOLAN, B.L. Phase relations of metamorphic amphiboles: Natural occurrence and theory. In: VEBLEN, D.R. \& RIBBE, P.H. (Eds). Amphiboles: Petrology and Experimental Phase Relations. Reviews in Mineralogy, Mineralogical Society of America, Washington, v. 9B, p. 1227, 1982.

SHAND, S.J. Eruptive Rocks: Their genesis, composition, and classification, with a chapter on meteorites. J. Wiley \& Sons, New York, 1943, 444 p.

SOARES, P.C.; FIORI, A.P.; CARVALHO, S.G. de. Tectônica colisional oblíqua entre o Bloco Paraná e a margem sul do cráton do São Francisco, no Maciço Guaxupé. In: CONGRESSO BRASILEIRO DE GEOLOGIA, n. 36., 1990, Natal, RN. Anais... Natal: SBG, 1990, v. 6, p. 2723-2734.
SPEAR, F.S. Metamorphic phase equilibria and pressuretemperature-time paths. Mineralogical Society of America, Washington, 1993. $789 \mathrm{p}$.

SUN, S.S. \& MCDONOUGH, W.F. Chemical and isotopic systematics of oceanic basalts: implications for mantle composition and process. Geological Society, London, Special Publication, v. 42, n. 1, p. 313-345, 1989.

TRACY, R.J.; ROBINSON, P.; THOMPSON, A.B. Garnet composition and zoning in the determination of temperature and pressure of metamorphism, central Massachusetts. American Mineralogist, v. 61, p. 762-775, 1976.

TROUW, R.A.J.; RIBEIRO, A.; PACIULLO, F.V.P.; HEILBRON, M. Os Grupos São João del Rei, Carrancas e Andrelândia, interpretados como a continuação dos Grupos Araxá e Canastra. In: CONGRESSO BRASILEIRO DE GEOLOGIA, 33, 1984, Rio de Janeiro. Anais...Rio de Janeiro: Sociedade Brasileira de Geologia, 1984, p. 3227-3240.

VALERIANO, C.M. The Southern Brasília Belt. In: HELIBRON, M.; CORDANI, U.G.; ALKMIM, F.F. (Eds). São Francisco Craton, Eastern Brazil - Tectonic Genealogy of a Miniature Continent. Regional Geology Reviews, Berlin, Heidelberg, Springer, p. 189-203, 2017.

VALERIANO, C.M.; MEDEIROS, S.R.; VAZ, G.S.; NETO, C.C. Sm-Nd isotope dilution TIMS analyses of BCR-1, AGV1 and G-2 USGS rock reference materials: first results from the LAGIR Laboratory at UERJ, Rio de Janeiro. In: SIMPÓSIO 45 ANOS DE GEOCRONOLOGIA NO BRASIL, 1, 2009, São Paulo. Boletim Resumos...São Paulo, 2009, p. 146-148.

WHITNEY, D.L. \& EVANS, B.W. Abbreviations for names of rock-forming minerals. American mineralogist, v. 95, n. 1, p. 185-187, 2010.

WOODSWORTH, G.J. Homogenization of zoned garnets from pelitic schists. The Canadian Mineralogist, v. 15, n. 2, p. 230 242, 1977.

YARDLEY, B.W.D. An empirical study of diffusion in garnet. American Mineralogist, v. 62, p. 793-800, 1977.

ZAKRUTKIN, V.V. \& GRIGORENKO, M.W. Titanium and alkalis in amphiboles in metamorphism. Doklady of the Academy of Sciences of the USSR, Earth Science Section, v. 173, p. 917-918, 1967.

ZANARDO, A. Análise petrográfica, estratigráfica e microestrutural da região de Guaxupé-Passos-Delfinópolis (MG). Rio Claro, 1992. 288p. Tese (Doutorado) - Instituto de Geociências e Ciências Exatas, Universidade Estadual Paulista.

ZANARDO, A. Pesquisa Geológica e de matérias primas cerâmicas do centro nordeste do Estado de São Paulo e vizinhanças - Sistematização crítica da produção Técnico Científica. Rio Claro, 2003. 304 p. Tese (Livre Docência). Instituto de Geociências e Ciências Exatas, Universidade Estadual Paulista.

ZANARDO, A.; DEL LAMA, E.A.; MORALES, N.; OLIVEIRA, M.A.F. Geologia da porção limítrofe entre os blocos São Paulo e Brasília. Revista Brasileira de Geociências, v.15, n. esp., p. 143-168, 1996.

ZANARDO, A.; MORALES, N.; OLIVEIRA, M.A.F.; DEL LAMA, E.A. Tectono-Lithologic associations of the Alterosa Paleo-Suture Zone - Southeastern Brazil. Revista UnG Geociências, v. 5, n. 1, p. 103-117, 2006.

ZHENG, Y.F. \& CHEN, R.X. Regional metamorphism at extreme conditions: implications for orogeny at convergent plate margins. Journal of Asian Earth Sciences, v. 145, p. 4673, 2017.

Submetido em 13 de maio de 2020 Aceito em 11 de agosto de 2020 
APÊNDICE - TABELAS SUPLEMENTARES

Tabela 1 - Análises de química mineral representativas de feldspatos (feldspato potássico e plagioclásio). Os átomos por unidade de fórmula foram calculados para 8 oxigênios, considerando todo o ferro presente como $\mathrm{Fe}_{2} \mathrm{O}_{3}$.

\begin{tabular}{|c|c|c|c|c|c|c|c|c|c|c|c|c|c|c|c|c|c|c|c|c|}
\hline \multirow{2}{*}{$\frac{\text { Amostra }}{\mathrm{SiO}_{2}}$} & \multicolumn{4}{|c|}{ P-5 } & \multicolumn{4}{|c|}{ P-5B } & \multicolumn{4}{|c|}{ P-5Cf } & \multicolumn{4}{|c|}{ P-9B } & \multicolumn{4}{|c|}{ P-13 } \\
\hline & 64.188 & 64.452 & 59.226 & 59.152 & 63.902 & 63.947 & 58.475 & 60.021 & 65.264 & 64.977 & 65.430 & 65.106 & 64.178 & 63.992 & 60.405 & 59.645 & 63.915 & 64.060 & 63.667 & 63.213 \\
\hline $\mathrm{TiO}_{2}$ & 0.000 & 0.000 & 0.000 & 0.000 & 0.000 & 0.000 & 0.000 & 0.000 & 0.000 & 0.000 & 0.000 & 0.000 & 0.000 & 0.000 & 0.000 & 0.000 & 0.000 & 0.000 & 0.000 & 0.000 \\
\hline $\mathrm{Al}_{2} \mathbf{O}_{3}$ & 18.985 & 19.270 & 26.148 & 26.066 & 18.910 & 18.851 & 25.888 & 24.648 & 19.013 & 19.051 & 22.597 & 22.662 & 18.906 & 18.926 & 25.202 & 25.520 & 18.944 & 18.923 & 22.630 & 22.563 \\
\hline $\mathrm{Cr}_{2} \mathrm{O}_{3}$ & 0.000 & 0.000 & 0.000 & 0.000 & 0.000 & 0.000 & 0.000 & 0.000 & 0.000 & 0.000 & 0.000 & 0.000 & 0.000 & 0.000 & 0.000 & 0.000 & 0.000 & 0.000 & 0.000 & 0.000 \\
\hline FeO & 0.000 & 0.000 & 0.000 & 0.000 & 0.000 & 0.000 & 0.000 & 0.000 & 0.000 & 0.000 & 0.000 & 0.000 & 0.000 & 0.000 & 0.000 & 0.000 & 0.000 & 0.000 & 0.000 & 0.000 \\
\hline $\mathrm{Fe}_{2} \mathrm{O}_{3}$ & 0.000 & 0.000 & 0.000 & 0.061 & 0.001 & 0.025 & 0.030 & 0.048 & 0.006 & 0.018 & 0.006 & 0.034 & 0.023 & 0.014 & 0.054 & 0.024 & 0.006 & 0.000 & 0.027 & 0.009 \\
\hline MnO & 0.000 & 0.000 & 0.000 & 0.000 & 0.000 & 0.000 & 0.000 & 0.000 & 0.000 & 0.000 & 0.000 & 0.000 & 0.000 & 0.000 & 0.000 & 0.000 & 0.000 & 0.000 & 0.000 & 0.000 \\
\hline MgO & 0.000 & 0.000 & 0.000 & 0.000 & 0.000 & 0.000 & 0.000 & 0.000 & 0.000 & 0.000 & 0.000 & 0.000 & 0.000 & 0.000 & 0.000 & 0.000 & 0.000 & 0.000 & 0.000 & 0.000 \\
\hline $\mathrm{BaO}$ & 1.135 & 0.933 & 0.000 & 0.000 & 0.859 & 0.873 & 0.000 & 0.007 & 0.000 & 0.000 & 0.000 & 0.000 & 0.892 & 0.802 & 0.033 & 0.006 & 0.821 & 0.702 & 0.007 & 0.000 \\
\hline $\mathrm{CaO}$ & 0.000 & 0.000 & 6.940 & 7.090 & 0.000 & 0.000 & 7.140 & 5.826 & 0.000 & 0.000 & 2.990 & 3.436 & 0.000 & 0.000 & 6.040 & 6.685 & 0.000 & 0.000 & 3.237 & 3.510 \\
\hline $\mathrm{Na}_{2} \mathrm{O}$ & 0.683 & 1.504 & 7.650 & 7.302 & 1.144 & 1.750 & 7.215 & 8.139 & 0.697 & 0.731 & 9.618 & 9.438 & 0.962 & 1.048 & 7.707 & 7.600 & 0.922 & 1.167 & 9.532 & 9.357 \\
\hline $\mathbf{K}_{2} \mathbf{O}$ & 14.443 & 13.596 & 0.226 & 0.255 & 14.153 & 13.218 & 0.246 & 0.206 & 14.812 & 14.735 & 0.182 & 0.152 & 14.386 & 14.367 & 0.349 & 0.220 & 14.483 & 14.208 & 0.204 & 0.186 \\
\hline Total & 99.434 & 99.755 & 100.190 & 99.926 & 98.969 & 98.664 & 98.994 & 98.895 & 99.792 & 99.512 & 100.823 & 100.828 & 99.347 & 99.149 & 99.790 & 99.700 & 99.091 & 99.060 & 99.304 & 98.838 \\
\hline $\mathrm{Si}$ & 2.981 & 2.972 & 2.637 & 2.639 & 2.977 & 2.979 & 2.635 & 2.698 & 2.996 & 2.991 & 2.853 & 2.842 & 2.980 & 2.977 & 2.690 & 2.664 & 2.976 & 2.979 & 2.826 & 2.821 \\
\hline Al & 1.039 & 1.048 & 1.372 & 1.371 & 1.039 & 1.035 & 1.375 & 1.306 & 1.029 & 1.034 & 1.162 & 1.166 & 1.035 & 1.038 & 1.323 & 1.344 & 1.040 & 1.037 & 1.184 & 1.187 \\
\hline $\mathrm{Fe}^{3+}$ & 0.000 & 0.000 & 0.000 & 0.002 & 0.000 & 0.001 & 0.001 & 0.002 & 0.000 & 0.001 & 0.000 & 0.001 & 0.001 & 0.000 & 0.002 & 0.001 & 0.000 & 0.000 & 0.001 & 0.000 \\
\hline $\mathbf{T i}$ & 0.000 & 0.000 & 0.000 & 0.000 & 0.000 & 0.000 & 0.000 & 0.000 & 0.000 & 0.000 & 0.000 & 0.000 & 0.000 & 0.000 & 0.000 & 0.000 & 0.000 & 0.000 & 0.000 & 0.000 \\
\hline $\mathrm{Cr}$ & 0.000 & 0.000 & 0.000 & 0.000 & 0.000 & 0.000 & 0.000 & 0.000 & 0.000 & 0.000 & 0.000 & 0.000 & 0.000 & 0.000 & 0.000 & 0.000 & 0.000 & 0.000 & 0.000 & 0.000 \\
\hline Mg & 0.000 & 0.000 & 0.000 & 0.000 & 0.000 & 0.000 & 0.000 & 0.000 & 0.000 & 0.000 & 0.000 & 0.000 & 0.000 & 0.000 & 0.000 & 0.000 & 0.000 & 0.000 & 0.000 & 0.000 \\
\hline $\mathrm{Fe}^{2+}$ & 0.000 & 0.000 & 0.000 & 0.000 & 0.000 & 0.000 & 0.000 & 0.000 & 0.000 & 0.000 & 0.000 & 0.000 & 0.000 & 0.000 & 0.000 & 0.000 & 0.000 & 0.000 & 0.000 & 0.000 \\
\hline Mn & 0.000 & 0.000 & 0.000 & 0.000 & 0.000 & 0.000 & 0.000 & 0.000 & 0.000 & 0.000 & 0.000 & 0.000 & 0.000 & 0.000 & 0.000 & 0.000 & 0.000 & 0.000 & 0.000 & 0.000 \\
\hline $\mathbf{B a}$ & 0.021 & 0.017 & 0.000 & 0.000 & 0.016 & 0.016 & 0.000 & 0.000 & 0.000 & 0.000 & 0.000 & 0.000 & 0.016 & 0.015 & 0.001 & 0.000 & 0.015 & 0.013 & 0.000 & 0.000 \\
\hline $\mathrm{Ca}$ & 0.000 & 0.000 & 0.331 & 0.339 & 0.000 & 0.000 & 0.345 & 0.281 & 0.000 & 0.000 & 0.140 & 0.161 & 0.000 & 0.000 & 0.288 & 0.320 & 0.000 & 0.000 & 0.154 & 0.168 \\
\hline $\mathrm{Na}$ & 0.061 & 0.134 & 0.660 & 0.632 & 0.103 & 0.158 & 0.630 & 0.709 & 0.062 & 0.065 & 0.813 & 0.799 & 0.087 & 0.095 & 0.666 & 0.658 & 0.083 & 0.105 & 0.820 & 0.810 \\
\hline $\mathbf{K}$ & 0.856 & 0.800 & 0.013 & 0.015 & 0.841 & 0.786 & 0.014 & 0.012 & 0.867 & 0.865 & 0.010 & 0.008 & 0.852 & 0.853 & 0.020 & 0.013 & 0.860 & 0.843 & 0.012 & 0.011 \\
\hline $\mathbf{A b}$ & 6.71 & 14.39 & 65.76 & 64.12 & 10.94 & 16.75 & 63.72 & 70.81 & 6.67 & 7.01 & 84.44 & 82.52 & 9.23 & 9.98 & 68.36 & 66.44 & 8.82 & 11.10 & 83.21 & 81.94 \\
\hline Anor & 0.00 & 0.00 & 32.97 & 34.41 & 0.00 & 0.00 & 34.85 & 28.01 & 0.00 & 0.00 & 14.51 & 16.60 & 0.00 & 0.00 & 29.61 & 32.30 & 0.00 & 0.00 & 15.62 & 16.99 \\
\hline Or & 93.29 & 85.61 & 1.28 & 1.47 & 89.06 & 83.25 & 1.43 & 1.18 & 93.33 & 92.99 & 1.05 & 0.87 & 90.77 & 90.02 & 2.04 & 1.27 & 91.18 & 88.90 & 1.17 & 1.07 \\
\hline
\end{tabular}


Tabela 2 - Análises de química mineral representativas de granada e proporção molecular. Os átomos por unidade de fórmula foram calculados para 12 oxigênios.

\begin{tabular}{|c|c|c|c|c|c|c|c|c|c|c|c|c|c|c|c|c|c|c|c|}
\hline \multirow{2}{*}{$\begin{array}{r}\text { Amostra } \\
\text { Análise }\end{array}$} & \multicolumn{5}{|c|}{ P-5 } & \multicolumn{7}{|c|}{ P-5B } & \multicolumn{7}{|c|}{ P-5Cf } \\
\hline & 1_5 & 1_6 & 1_7 & 1_8 & 1_9 & 5_1 & 5_2 & 5_4 & 5_5 & 5_7 & 5_8 & 5_9 & 3_1 & 3_2 & 3_3 & 3_4 & 3_5 & 3_6 & 3_7 \\
\hline $\mathrm{SiO}_{2}$ & 36.516 & 36.801 & 37.093 & 36.743 & 36.941 & 36.590 & 36.330 & 36.550 & 36.410 & 36.200 & 36.210 & 36.310 & 37.300 & 37.640 & 37.030 & 37.310 & 37.310 & 37.220 & 36.850 \\
\hline $\mathrm{TiO}_{2}$ & 0.016 & 0.043 & 0.031 & 0.027 & 0.009 & 0.030 & 0.050 & 0.040 & 0.030 & 0.000 & 0.030 & 0.040 & 0.040 & 0.050 & 0.050 & 0.040 & 0.070 & 0.080 & 0.040 \\
\hline $\mathbf{A l}_{2} \mathbf{O}_{3}$ & 19.949 & 20.162 & 20.134 & 19.866 & 20.245 & 20.600 & 20.400 & 20.560 & 20.420 & 20.780 & 20.680 & 20.390 & 20.950 & 21.040 & 21.090 & 20.890 & 20.980 & 20.700 & 20.810 \\
\hline $\mathrm{Cr}_{2} \mathrm{O}_{3}$ & 0.000 & 0.000 & 0.000 & 0.001 & 0.001 & 0.000 & 0.000 & 0.000 & 0.010 & 0.000 & 0.010 & 0.000 & 0.000 & 0.000 & 0.000 & 0.010 & 0.000 & 0.000 & 0.000 \\
\hline $\mathrm{Fe}_{2} \mathrm{O}_{3}$ & 2.237 & 1.528 & 1.768 & 1.947 & 1.904 & 3.250 & 3.750 & 3.130 & 3.200 & 3.470 & 3.620 & 3.350 & 1.330 & 0.450 & 1.100 & 0.740 & 1.080 & 0.800 & 1.350 \\
\hline $\mathrm{FeO}$ & 30.751 & 31.293 & 31.256 & 31.015 & 30.415 & 29.220 & 28.750 & 28.660 & 28.750 & 28.810 & 28.740 & 29.170 & 30.010 & 30.530 & 29.620 & 30.160 & 29.370 & 29.610 & 29.460 \\
\hline MnO & 0.862 & 0.775 & 0.722 & 0.797 & 0.819 & 0.670 & 0.640 & 0.660 & 0.670 & 0.680 & 0.690 & 0.690 & 0.600 & 0.570 & 0.600 & 0.750 & 0.530 & 0.530 & 1.000 \\
\hline MgO & 1.103 & 1.176 & 1.181 & 1.210 & 1.098 & 1.070 & 1.140 & 1.040 & 1.080 & 1.070 & 1.110 & 1.120 & 1.170 & 1.260 & 1.090 & 0.890 & 1.220 & 1.190 & 0.660 \\
\hline $\mathrm{CaO}$ & 7.922 & 7.770 & 8.069 & 7.856 & 8.636 & 9.290 & 9.350 & 9.760 & 9.510 & 9.180 & 9.260 & 9.030 & 9.240 & 9.120 & 9.450 & 9.410 & 9.750 & 9.560 & 9.700 \\
\hline $\mathrm{Na}_{2} \mathrm{O}$ & 0.005 & 0.000 & 0.008 & 0.000 & 0.000 & 0.010 & 0.020 & 0.010 & 0.010 & 0.030 & 0.010 & 0.000 & 0.020 & 0.010 & 0.000 & 0.020 & 0.030 & 0.020 & 0.000 \\
\hline $\mathbf{K}_{2} \mathbf{O}$ & 0.004 & 0.000 & 0.000 & 0.013 & 0.009 & 0.010 & 0.000 & 0.010 & 0.000 & 0.000 & 0.000 & 0.000 & 0.010 & 0.000 & 0.010 & 0.000 & 0.000 & 0.000 & 0.000 \\
\hline Total & 99.141 & 99.395 & 100.085 & 99.280 & 99.886 & 100.740 & 100.430 & 100.400 & 100.090 & 100.220 & 100.360 & 100.100 & 100.670 & 100.660 & 100.040 & 100.210 & 100.330 & 99.690 & 99.870 \\
\hline Si & 2.972 & 2.985 & 2.987 & 2.985 & 2.978 & 2.929 & 2.919 & 2.932 & 2.932 & 2.912 & 2.909 & 2.927 & 2.975 & 2.997 & 2.968 & 2.990 & 2.978 & 2.992 & 2.969 \\
\hline $\mathbf{T i}$ & 0.001 & 0.003 & 0.002 & 0.002 & 0.001 & 0.002 & 0.003 & 0.002 & 0.002 & 0.000 & 0.002 & 0.003 & 0.002 & 0.003 & 0.003 & 0.002 & 0.004 & 0.005 & 0.002 \\
\hline Al & 1.912 & 1.926 & 1.910 & 1.901 & 1.922 & 1.944 & 1.932 & 1.944 & 1.939 & 1.970 & 1.960 & 1.938 & 1.970 & 1.975 & 1.993 & 1.974 & 1.974 & 1.961 & 1.977 \\
\hline $\mathrm{Cr}$ & 0.000 & 0.000 & 0.000 & 0.000 & 0.000 & 0.000 & 0.000 & 0.000 & 0.001 & 0.000 & 0.000 & 0.000 & 0.000 & 0.000 & 0.000 & 0.001 & 0.000 & 0.000 & 0.000 \\
\hline $\mathbf{F e}^{3+}$ & 0.137 & 0.093 & 0.107 & 0.119 & 0.115 & 0.196 & 0.227 & 0.189 & 0.194 & 0.210 & 0.219 & 0.203 & 0.080 & 0.027 & 0.066 & 0.045 & 0.065 & 0.048 & 0.082 \\
\hline $\mathrm{Fe}^{2+}$ & 2.093 & 2.123 & 2.105 & 2.107 & 2.050 & 1.956 & 1.932 & 1.923 & 1.936 & 1.938 & 1.931 & 1.967 & 2.001 & 2.033 & 1.986 & 2.022 & 1.960 & 1.990 & 1.985 \\
\hline Mn & 0.059 & 0.053 & 0.049 & 0.055 & 0.056 & 0.046 & 0.044 & 0.045 & 0.045 & 0.046 & 0.047 & 0.047 & 0.041 & 0.038 & 0.041 & 0.051 & 0.036 & 0.036 & 0.068 \\
\hline Mg & 0.134 & 0.142 & 0.142 & 0.147 & 0.132 & 0.128 & 0.136 & 0.124 & 0.129 & 0.128 & 0.133 & 0.134 & 0.139 & 0.149 & 0.130 & 0.106 & 0.145 & 0.142 & 0.079 \\
\hline Ca & 0.691 & 0.675 & 0.696 & 0.684 & 0.746 & 0.797 & 0.805 & 0.839 & 0.820 & 0.791 & 0.797 & 0.780 & 0.789 & 0.778 & 0.811 & 0.808 & 0.834 & 0.823 & 0.838 \\
\hline $\mathrm{Na}$ & 0.001 & 0.000 & 0.001 & 0.000 & 0.000 & 0.002 & 0.002 & 0.001 & 0.001 & 0.004 & 0.001 & 0.001 & 0.002 & 0.001 & 0.000 & 0.003 & 0.004 & 0.002 & 0.000 \\
\hline $\mathbf{K}$ & 0.000 & 0.000 & 0.000 & 0.000 & 0.000 & 0.001 & 0.000 & 0.001 & 0.000 & 0.000 & 0.000 & 0.000 & 0.001 & 0.000 & 0.001 & 0.000 & 0.000 & 0.000 & 0.000 \\
\hline Alm & 70.29 & 70.91 & 70.32 & 70.42 & 68.71 & 66.83 & 66.23 & 65.61 & 66.08 & 66.76 & 66.40 & 67.18 & 67.37 & 67.81 & 66.91 & 67.69 & 65.88 & 66.53 & 66.84 \\
\hline Prp & 4.49 & 4.75 & 4.74 & 4.90 & 4.42 & 4.37 & 4.66 & 4.23 & 4.40 & 4.41 & 4.57 & 4.58 & 4.68 & 4.97 & 4.38 & 3.55 & 4.87 & 4.75 & 2.66 \\
\hline Sps & 2.00 & 1.78 & 1.65 & 1.83 & 1.87 & 1.57 & 1.51 & 1.54 & 1.54 & 1.58 & 1.62 & 1.61 & 1.38 & 1.27 & 1.38 & 1.71 & 1.21 & 1.20 & 2.29 \\
\hline Grs & 16.42 & 17.91 & 17.92 & 16.92 & 19.26 & 18.07 & 17.08 & 19.76 & 18.85 & 17.61 & 17.36 & 17.16 & 22.66 & 24.60 & 24.12 & 24.77 & 24.85 & 25.13 & 24.23 \\
\hline Adr & 6.78 & 4.65 & 5.34 & 5.93 & 5.73 & 9.16 & 10.51 & 8.86 & 9.09 & 9.63 & 10.05 & 9.48 & 3.90 & 1.35 & 3.21 & 2.23 & 3.19 & 2.39 & 3.98 \\
\hline Uv & 0.00 & 0.00 & 0.00 & 0.00 & 0.00 & 0.00 & 0.00 & 0.00 & 0.05 & 0.00 & 0.00 & 0.00 & 0.00 & 0.00 & 0.00 & 0.05 & 0.00 & 0.00 & 0.00 \\
\hline
\end{tabular}


Tabela 2 - continuação

\begin{tabular}{|c|c|c|c|c|c|c|c|c|c|c|c|}
\hline \multirow{2}{*}{$\begin{array}{l}\text { Amostra } \\
\text { Análise }\end{array}$} & \multicolumn{4}{|c|}{ P-9B } & \multicolumn{7}{|c|}{ P-13 } \\
\hline & 10_1 & 10_2 & 10_3 & 10_4 & 10_1 & $10 \_2$ & $10 \_3$ & $10 \_4$ & $10 \_6$ & $10 \_7$ & $10 \_8$ \\
\hline $\mathrm{SiO}_{2}$ & 35.790 & 36.010 & 35.860 & 35.530 & 36.820 & 36.560 & 36.420 & 36.340 & 36.310 & 36.620 & 36.610 \\
\hline $\mathrm{TiO}_{2}$ & 0.030 & 0.030 & 0.030 & 0.040 & 0.050 & 0.050 & 0.020 & 0.030 & 0.030 & 0.030 & 0.050 \\
\hline $\mathrm{Al}_{2} \mathbf{O}_{3}$ & 20.240 & 20.390 & 20.480 & 20.340 & 20.880 & 20.830 & 20.960 & 20.840 & 20.730 & 20.760 & 20.580 \\
\hline $\mathrm{Cr}_{2} \mathrm{O}_{3}$ & 0.000 & 0.000 & 0.000 & 0.010 & 0.000 & 0.010 & 0.010 & 0.010 & 0.000 & 0.000 & 0.000 \\
\hline $\mathrm{Fe}_{2} \mathrm{O}_{3}$ & 4.180 & 4.150 & 4.670 & 4.300 & 3.080 & 3.120 & 3.350 & 3.540 & 3.620 & 3.400 & 3.450 \\
\hline $\mathrm{FeO}$ & 29.300 & 29.690 & 29.810 & 29.290 & 28.140 & 27.400 & 27.900 & 27.860 & 27.910 & 28.360 & 28.070 \\
\hline MnO & 0.660 & 0.680 & 0.660 & 0.610 & 0.620 & 0.550 & 0.720 & 0.690 & 0.660 & 0.830 & 1.040 \\
\hline MgO & 1.000 & 1.210 & 1.350 & 1.190 & 1.230 & 1.150 & 1.020 & 1.120 & 1.170 & 0.980 & 0.860 \\
\hline $\mathrm{CaO}$ & 8.580 & 8.180 & 7.660 & 8.180 & 10.160 & 10.710 & 10.200 & 10.040 & 9.920 & 10.020 & 10.140 \\
\hline $\mathrm{Na}_{2} \mathrm{O}$ & 0.010 & 0.010 & 0.040 & 0.000 & 0.020 & 0.010 & 0.010 & 0.010 & 0.010 & 0.010 & 0.040 \\
\hline $\mathbf{K}_{2} \mathbf{O}$ & 0.000 & 0.010 & 0.010 & 0.000 & 0.000 & 0.000 & 0.010 & 0.000 & 0.000 & 0.000 & 0.000 \\
\hline Total & 99.800 & 100.360 & 100.570 & 99.480 & 101.010 & 100.390 & 100.610 & 100.470 & 100.370 & 101.010 & 100.830 \\
\hline Si & 2.904 & 2.904 & 2.888 & 2.890 & 2.928 & 2.922 & 2.911 & 2.909 & 2.910 & 2.921 & 2.926 \\
\hline $\mathbf{T i}$ & 0.002 & 0.002 & 0.002 & 0.002 & 0.003 & 0.003 & 0.001 & 0.002 & 0.002 & 0.002 & 0.003 \\
\hline Al & 1.936 & 1.939 & 1.944 & 1.951 & 1.957 & 1.963 & 1.975 & 1.967 & 1.959 & 1.952 & 1.940 \\
\hline $\mathrm{Cr}$ & 0.000 & 0.000 & 0.000 & 0.000 & 0.000 & 0.001 & 0.000 & 0.001 & 0.000 & 0.000 & 0.000 \\
\hline $\mathrm{Fe}^{3+}$ & 0.255 & 0.252 & 0.283 & 0.263 & 0.184 & 0.187 & 0.202 & 0.213 & 0.219 & 0.204 & 0.208 \\
\hline $\mathrm{Fe}^{2+}$ & 1.988 & 2.003 & 2.008 & 1.993 & 1.872 & 1.831 & 1.865 & 1.865 & 1.871 & 1.891 & 1.877 \\
\hline Mn & 0.045 & 0.047 & 0.045 & 0.042 & 0.042 & 0.037 & 0.049 & 0.047 & 0.045 & 0.056 & 0.070 \\
\hline Mg & 0.121 & 0.146 & 0.163 & 0.144 & 0.146 & 0.137 & 0.121 & 0.134 & 0.140 & 0.117 & 0.102 \\
\hline Ca & 0.746 & 0.707 & 0.661 & 0.713 & 0.865 & 0.918 & 0.873 & 0.861 & 0.852 & 0.857 & 0.868 \\
\hline $\mathrm{Na}$ & 0.002 & 0.001 & 0.006 & 0.000 & 0.003 & 0.001 & 0.002 & 0.002 & 0.002 & 0.001 & 0.005 \\
\hline $\mathbf{K}$ & 0.000 & 0.001 & 0.001 & 0.000 & 0.000 & 0.000 & 0.001 & 0.000 & 0.000 & 0.000 & 0.000 \\
\hline Alm & 68.55 & 69.00 & 69.79 & 68.91 & 64.00 & 62.64 & 64.13 & 64.16 & 64.34 & 64.74 & 64.35 \\
\hline Prp & 4.17 & 5.03 & 5.67 & 4.98 & 4.99 & 4.69 & 4.16 & 4.61 & 4.81 & 4.01 & 3.50 \\
\hline Sps & 1.55 & 1.62 & 1.56 & 1.45 & 1.44 & 1.27 & 1.69 & 1.62 & 1.55 & 1.92 & 2.40 \\
\hline Grs & 14.09 & 12.85 & 10.27 & 12.78 & 20.98 & 22.67 & 20.74 & 19.81 & 19.24 & 19.88 & 20.07 \\
\hline And & 11.64 & 11.50 & 12.71 & 11.88 & 8.59 & 8.69 & 9.28 & 9.77 & 10.06 & 9.46 & 9.68 \\
\hline $\mathbf{U v}$ & 0.00 & 0.00 & 0.00 & 0.00 & 0.00 & 0.05 & 0.00 & 0.05 & 0.00 & 0.00 & 0.00 \\
\hline
\end{tabular}


Tabela 3 - Análises de química mineral representativas de biotita. Os átomos por unidade de fórmula foram calculados em base anidra para 22 oxigênios, considerando todo o ferro presente como FeO.

\begin{tabular}{|c|c|c|c|c|c|c|c|c|c|c|c|c|c|c|c|c|c|c|c|}
\hline \multirow{2}{*}{$\begin{array}{c}\text { Amostra } \\
\mathrm{SiO}_{2}\end{array}$} & \multicolumn{4}{|c|}{ P-5 } & \multicolumn{4}{|c|}{ P-5B } & \multicolumn{3}{|c|}{ P-5Cf } & \multicolumn{4}{|c|}{ P-9B } & \multicolumn{4}{|c|}{ P-13 } \\
\hline & 34.359 & 34.510 & 34.422 & 34.172 & 34.288 & 34.699 & 34.243 & 34.266 & 34.467 & 34.123 & 33.963 & 34.425 & 34.311 & 34.190 & 34.154 & 34.635 & 34.456 & 34.128 & 34.337 \\
\hline $\mathrm{TiO}_{2}$ & 5.011 & 5.103 & 5.064 & 5.090 & 5.187 & 5.041 & 4.962 & 5.035 & 3.365 & 3.629 & 3.684 & 3.981 & 4.072 & 3.922 & 3.773 & 4.833 & 4.815 & 5.047 & 4.902 \\
\hline $\mathbf{A l}_{2} \mathbf{O}_{3}$ & 14.550 & 14.214 & 14.629 & 14.215 & 14.542 & 14.747 & 14.579 & 14.759 & 15.916 & 15.992 & 15.919 & 15.002 & 14.975 & 14.900 & 14.746 & 14.311 & 14.514 & 14.669 & 14.320 \\
\hline $\mathrm{Cr}_{2} \mathrm{O}_{3}$ & 0.007 & 0.003 & 0.010 & 0.000 & 0.000 & 0.006 & 0.013 & 0.000 & 0.000 & 0.006 & 0.004 & 0.000 & 0.001 & 0.000 & 0.000 & 0.000 & 0.000 & 0.000 & 0.000 \\
\hline $\mathrm{FeO}$ & 29.771 & 29.531 & 29.198 & 29.676 & 31.859 & 31.931 & 31.669 & 32.389 & 32.264 & 32.271 & 32.436 & 31.868 & 32.114 & 31.313 & 32.708 & 31.605 & 31.623 & 31.220 & 32.145 \\
\hline $\mathrm{Fe}_{2} \mathrm{O}_{3}$ & 0.000 & 0.000 & 0.000 & 0.000 & 0.000 & 0.000 & 0.000 & 0.000 & 0.000 & 0.000 & 0.000 & 0.000 & 0.000 & 0.000 & 0.000 & 0.000 & 0.000 & 0.000 & 0.000 \\
\hline MnO & 0.041 & 0.043 & 0.063 & 0.026 & 0.034 & 0.041 & 0.014 & 0.025 & 0.091 & 0.060 & 0.018 & 0.020 & 0.040 & 0.052 & 0.048 & 0.046 & 0.045 & 0.067 & 0.034 \\
\hline MgO & 3.576 & 3.793 & 3.844 & 3.593 & 3.904 & 3.942 & 3.938 & 3.753 & 3.063 & 2.685 & 2.736 & 4.094 & 4.068 & 4.018 & 4.206 & 4.123 & 4.075 & 3.893 & 4.035 \\
\hline $\mathrm{CaO}$ & 0.000 & 0.000 & 0.000 & 0.000 & 0.000 & 0.000 & 0.000 & 0.000 & 0.000 & 0.000 & 0.000 & 0.000 & 0.000 & 0.000 & 0.000 & 0.000 & 0.000 & 0.000 & 0.000 \\
\hline $\mathrm{Na}_{2} \mathrm{O}$ & 0.041 & 0.052 & 0.060 & 0.035 & 0.038 & 0.047 & 0.055 & 0.057 & 0.055 & 0.042 & 0.047 & 0.025 & 0.049 & 0.187 & 0.054 & 0.065 & 0.042 & 0.047 & 0.019 \\
\hline $\mathbf{K}_{2} \mathbf{O}$ & 8.775 & 8.658 & 8.775 & 8.802 & 8.984 & 8.931 & 8.887 & 8.945 & 8.752 & 8.758 & 8.713 & 8.559 & 8.798 & 8.686 & 8.750 & 8.751 & 8.697 & 8.718 & 8.801 \\
\hline Total & 96.497 & 96.308 & 96.422 & 95.955 & 96.840 & 96.740 & 95.910 & 95.600 & 96.790 & 95.010 & 93.150 & 95.430 & 94.960 & 95.760 & 95.410 & 96.670 & 96.030 & 97.360 & 96.090 \\
\hline Si & 5.476 & 5.503 & 5.474 & 5.483 & 5.375 & 5.398 & 5.387 & 5.359 & 5.439 & 5.414 & 5.397 & 5.424 & 5.398 & 5.428 & 5.392 & 5.438 & 5.416 & 5.387 & 5.399 \\
\hline $\mathrm{Al}^{\mathrm{IV}}$ & 2.524 & 2.497 & 2.526 & 2.517 & 2.625 & 2.602 & 2.613 & 2.641 & 2.561 & 2.586 & 2.603 & 2.576 & 2.602 & 2.572 & 2.608 & 2.562 & 2.584 & 2.613 & 2.601 \\
\hline $\mathrm{Al}^{\mathrm{VI}}$ & 0.210 & 0.176 & 0.217 & 0.172 & 0.062 & 0.102 & 0.091 & 0.080 & 0.401 & 0.405 & 0.379 & 0.211 & 0.175 & 0.217 & 0.136 & 0.088 & 0.105 & 0.117 & 0.053 \\
\hline $\mathbf{T i}$ & 0.601 & 0.612 & 0.606 & 0.614 & 0.611 & 0.590 & 0.587 & 0.592 & 0.399 & 0.433 & 0.440 & 0.472 & 0.482 & 0.468 & 0.448 & 0.571 & 0.569 & 0.599 & 0.580 \\
\hline $\mathrm{Cr}$ & 0.001 & 0.000 & 0.001 & 0.000 & 0.000 & 0.001 & 0.002 & 0.000 & 0.000 & 0.001 & 0.001 & 0.000 & 0.000 & 0.000 & 0.000 & 0.000 & 0.000 & 0.000 & 0.000 \\
\hline $\mathrm{Fe}^{2+}$ & 3.968 & 3.939 & 3.883 & 3.982 & 4.176 & 4.154 & 4.167 & 4.236 & 4.258 & 4.282 & 4.311 & 4.200 & 4.225 & 4.158 & 4.318 & 4.150 & 4.157 & 4.122 & 4.227 \\
\hline $\mathrm{Fe}^{3+}$ & 0.000 & 0.000 & 0.000 & 0.000 & 0.000 & 0.000 & 0.000 & 0.000 & 0.000 & 0.000 & 0.000 & 0.000 & 0.000 & 0.000 & 0.000 & 0.000 & 0.000 & 0.000 & 0.000 \\
\hline Mn & 0.006 & 0.006 & 0.008 & 0.004 & 0.005 & 0.005 & 0.002 & 0.003 & 0.012 & 0.008 & 0.002 & 0.003 & 0.005 & 0.007 & 0.006 & 0.006 & 0.006 & 0.009 & 0.005 \\
\hline Mg & 0.849 & 0.901 & 0.911 & 0.859 & 0.912 & 0.914 & 0.923 & 0.875 & 0.720 & 0.635 & 0.648 & 0.961 & 0.954 & 0.951 & 0.990 & 0.965 & 0.955 & 0.916 & 0.945 \\
\hline Ca & 0.000 & 0.000 & 0.000 & 0.000 & 0.000 & 0.000 & 0.000 & 0.000 & 0.000 & 0.000 & 0.000 & 0.000 & 0.000 & 0.000 & 0.000 & 0.000 & 0.000 & 0.000 & 0.000 \\
\hline $\mathrm{Na}$ & 0.013 & 0.016 & 0.019 & 0.011 & 0.012 & 0.014 & 0.017 & 0.017 & 0.017 & 0.013 & 0.014 & 0.008 & 0.015 & 0.058 & 0.017 & 0.020 & 0.013 & 0.014 & 0.006 \\
\hline $\mathbf{K}$ & 1.784 & 1.762 & 1.780 & 1.802 & 1.797 & 1.772 & 1.784 & 1.785 & 1.762 & 1.773 & 1.766 & 1.721 & 1.766 & 1.759 & 1.762 & 1.753 & 1.744 & 1.756 & 1.765 \\
\hline $\mathrm{Fe} / \mathrm{Fe}+\mathrm{Mg}$ & 0.824 & 0.814 & 0.810 & 0.823 & 0.821 & 0.820 & 0.819 & 0.829 & 0.855 & 0.871 & 0.869 & 0.814 & 0.816 & 0.814 & 0.814 & 0.811 & 0.813 & 0.818 & 0.817 \\
\hline $\mathrm{Mg} / \mathrm{Mg}+\mathrm{Fe}$ & 0.176 & 0.186 & 0.190 & 0.177 & 0.179 & 0.180 & 0.181 & 0.171 & 0.145 & 0.129 & 0.131 & 0.186 & 0.184 & 0.186 & 0.186 & 0.189 & 0.187 & 0.182 & 0.183 \\
\hline
\end{tabular}


Tabela 4 - Análises de química mineral representativas de anfibólio. Os átomos por unidade de fórmula foram calculados em base anidra para 23 oxigênios, considerando todo o ferro presente como FeO.

\begin{tabular}{|c|c|c|c|c|c|c|c|c|c|c|c|c|c|c|c|c|c|c|c|c|}
\hline \multirow{2}{*}{$\begin{array}{c}\text { Amostra } \\
\mathrm{SiO}_{2}\end{array}$} & \multicolumn{4}{|c|}{ P-5 } & \multicolumn{4}{|c|}{ P-5B } & \multicolumn{4}{|c|}{ P-5Cf } & \multicolumn{4}{|c|}{ P-9B } & \multicolumn{4}{|c|}{ P-13 } \\
\hline & 40.397 & 40.407 & 40.602 & 40.269 & 40.492 & 40.477 & 40.177 & 40.340 & 39.260 & 38.981 & 39.238 & 38.762 & 40.198 & 39.999 & 40.283 & 40.141 & 39.661 & 39.482 & 39.754 & 39.797 \\
\hline $\mathrm{TiO}_{2}$ & 1.858 & 1.816 & 1.604 & 0.564 & 1.278 & 1.632 & 1.800 & 1.762 & 1.054 & 1.149 & 1.293 & 1.269 & 2.117 & 1.850 & 1.848 & 1.999 & 1.692 & 2.045 & 1.871 & 2.198 \\
\hline $\mathrm{Al}_{2} \mathrm{O}_{3}$ & 11.306 & 11.642 & 11.649 & 12.206 & 11.999 & 12.020 & 11.943 & 11.923 & 12.710 & 12.316 & 12.452 & 12.593 & 11.363 & 10.810 & 11.486 & 11.272 & 12.316 & 11.998 & 12.372 & 11.887 \\
\hline $\mathrm{Cr}_{2} \mathrm{O}_{3}$ & 0.017 & 0.000 & 0.024 & 0.002 & 0.000 & 0.009 & 0.006 & 0.007 & 0.010 & 0.006 & 0.017 & 0.000 & 0.020 & 0.007 & 0.016 & 0.009 & 0.002 & 0.000 & 0.002 & 0.017 \\
\hline $\mathrm{FeO}$ & 26.572 & 26.959 & 26.763 & 28.136 & 25.779 & 25.581 & 26.309 & 26.121 & 26.872 & 26.595 & 26.629 & 26.149 & 25.831 & 26.424 & 26.312 & 26.278 & 25.612 & 26.358 & 26.218 & 26.129 \\
\hline $\mathrm{Fe}_{2} \mathrm{O}_{3}$ & 0.000 & 0.000 & 0.000 & 0.000 & 0.000 & 0.000 & 0.000 & 0.000 & 0.000 & 0.000 & 0.000 & 0.000 & 0.000 & 0.000 & 0.000 & 0.000 & 0.000 & 0.000 & 0.000 & 0.000 \\
\hline MnO & 0.051 & 0.079 & 0.062 & 0.030 & 0.061 & 0.068 & 0.048 & 0.056 & 0.127 & 0.129 & 0.109 & 0.128 & 0.083 & 0.054 & 0.049 & 0.082 & 0.066 & 0.084 & 0.070 & 0.113 \\
\hline MgO & 3.460 & 3.356 & 3.687 & 3.151 & 3.884 & 3.752 & 3.430 & 3.628 & 2.800 & 2.640 & 2.557 & 2.486 & 3.636 & 3.855 & 3.604 & 3.643 & 3.497 & 3.460 & 3.281 & 3.451 \\
\hline $\mathrm{CaO}$ & 10.917 & 10.819 & 10.865 & 10.602 & 11.061 & 11.047 & 11.150 & 11.008 & 10.920 & 10.966 & 10.784 & 10.977 & 10.884 & 10.895 & 10.791 & 10.687 & 11.042 & 10.591 & 11.094 & 10.928 \\
\hline $\mathrm{Na}_{2} \mathrm{O}$ & 1.522 & 1.566 & 1.538 & 1.566 & 1.482 & 1.468 & 1.545 & 1.470 & 1.271 & 1.355 & 1.360 & 1.191 & 1.545 & 1.526 & 1.508 & 1.638 & 1.397 & 1.542 & 1.289 & 1.601 \\
\hline $\mathbf{K}_{2} \mathbf{O}$ & 1.635 & 1.565 & 1.542 & 1.489 & 1.598 & 1.550 & 1.609 & 1.624 & 1.614 & 1.632 & 1.620 & 1.718 & 1.554 & 1.577 & 1.587 & 1.620 & 1.743 & 1.741 & 1.830 & 1.759 \\
\hline Total & 97.735 & 98.209 & 98.336 & 98.015 & 98.100 & 98.640 & 98.620 & 98.040 & 98.890 & 98.080 & 98.720 & 98.190 & 98.060 & 98.020 & 97.770 & 98.050 & 97.740 & 98.450 & 98.770 & 98.260 \\
\hline Si & 6.397 & 6.372 & 6.383 & 6.385 & 6.386 & 6.378 & 6.337 & 6.356 & 6.301 & 6.320 & 6.331 & 6.305 & 6.379 & 6.391 & 6.384 & 6.377 & 6.307 & 6.285 & 6.289 & 6.295 \\
\hline $\mathbf{A l}^{\mathrm{IV}}$ & 1.603 & 1.628 & 1.617 & 1.615 & 1.614 & 1.622 & 1.663 & 1.644 & 1.699 & 1.680 & 1.669 & 1.695 & 1.621 & 1.609 & 1.616 & 1.623 & 1.693 & 1.715 & 1.711 & 1.705 \\
\hline $\mathrm{Al}^{\mathrm{VI}}$ & 0.508 & 0.536 & 0.543 & 0.667 & 0.617 & 0.611 & 0.558 & 0.571 & 0.706 & 0.674 & 0.700 & 0.720 & 0.505 & 0.427 & 0.530 & 0.488 & 0.616 & 0.537 & 0.597 & 0.511 \\
\hline $\mathbf{T i}$ & 0.221 & 0.215 & 0.190 & 0.067 & 0.152 & 0.193 & 0.214 & 0.209 & 0.127 & 0.140 & 0.157 & 0.155 & 0.253 & 0.222 & 0.220 & 0.239 & 0.202 & 0.245 & 0.223 & 0.261 \\
\hline $\mathbf{F e}^{3+}$ & 0.000 & 0.000 & 0.000 & 0.000 & 0.000 & 0.000 & 0.000 & 0.000 & 0.000 & 0.000 & 0.000 & 0.000 & 0.000 & 0.000 & 0.000 & 0.000 & 0.000 & 0.000 & 0.000 & 0.000 \\
\hline $\mathrm{Cr}$ & 0.002 & 0.000 & 0.003 & 0.000 & 0.000 & 0.001 & 0.001 & 0.001 & 0.001 & 0.001 & 0.002 & 0.000 & 0.003 & 0.001 & 0.002 & 0.001 & 0.000 & 0.000 & 0.000 & 0.002 \\
\hline Mg & 0.817 & 0.789 & 0.864 & 0.745 & 0.913 & 0.881 & 0.806 & 0.852 & 0.670 & 0.638 & 0.615 & 0.603 & 0.860 & 0.918 & 0.851 & 0.862 & 0.829 & 0.821 & 0.774 & 0.813 \\
\hline $\mathbf{F e}^{2+} \mathbf{Y}$ & 3.452 & 3.460 & 3.401 & 3.521 & 3.318 & 3.314 & 3.421 & 3.368 & 3.496 & 3.548 & 3.526 & 3.522 & 3.380 & 3.432 & 3.397 & 3.410 & 3.353 & 3.398 & 3.407 & 3.412 \\
\hline $\mathrm{Fe}^{2+} \mathrm{X}$ & 0.067 & 0.095 & 0.118 & 0.210 & 0.082 & 0.057 & 0.049 & 0.074 & 0.111 & 0.058 & 0.067 & 0.035 & 0.048 & 0.099 & 0.091 & 0.082 & 0.054 & 0.112 & 0.062 & 0.044 \\
\hline Mn & 0.007 & 0.011 & 0.008 & 0.004 & 0.008 & 0.009 & 0.006 & 0.007 & 0.017 & 0.018 & 0.015 & 0.018 & 0.011 & 0.007 & 0.007 & 0.011 & 0.009 & 0.011 & 0.009 & 0.015 \\
\hline Ca & 1.852 & 1.828 & 1.830 & 1.801 & 1.869 & 1.865 & 1.884 & 1.858 & 1.878 & 1.905 & 1.864 & 1.913 & 1.851 & 1.865 & 1.832 & 1.819 & 1.881 & 1.807 & 1.881 & 1.852 \\
\hline $\mathrm{Na}_{\mathrm{A}}$ & 0.467 & 0.479 & 0.469 & 0.481 & 0.453 & 0.449 & 0.473 & 0.449 & 0.396 & 0.426 & 0.425 & 0.376 & 0.475 & 0.473 & 0.463 & 0.505 & 0.431 & 0.476 & 0.395 & 0.491 \\
\hline $\mathbf{K}_{\mathbf{A}}$ & 0.330 & 0.315 & 0.309 & 0.301 & 0.322 & 0.312 & 0.324 & 0.326 & 0.330 & 0.338 & 0.333 & 0.357 & 0.315 & 0.321 & 0.321 & 0.328 & 0.354 & 0.354 & 0.369 & 0.355 \\
\hline $\mathrm{Fe} / \mathrm{Fe}+\mathrm{Mg}$ & 0.809 & 0.814 & 0.797 & 0.825 & 0.784 & 0.790 & 0.809 & 0.798 & 0.839 & 0.848 & 0.852 & 0.854 & 0.797 & 0.789 & 0.800 & 0.798 & 0.802 & 0.805 & 0.815 & 0.807 \\
\hline $\mathrm{Mg} / \mathrm{Mg}+\mathrm{Fe}$ & 0.191 & 0.186 & 0.203 & 0.175 & 0.216 & 0.210 & 0.191 & 0.202 & 0.161 & 0.152 & 0.148 & 0.146 & 0.203 & 0.211 & 0.200 & 0.202 & 0.198 & 0.195 & 0.185 & 0.193 \\
\hline
\end{tabular}


Tabela 5 - Análises de química mineral representativas de piroxênio. Os átomos por unidade de fórmula foram calculados na base para 6 oxigênios, considerando todo o ferro presente como $\mathrm{FeO}$.

\begin{tabular}{|c|c|c|c|c|c|c|c|c|c|c|c|c|c|c|c|c|c|c|c|c|}
\hline \multirow{2}{*}{$\frac{\text { Amostra }}{\mathrm{SiO}_{2}}$} & \multicolumn{5}{|c|}{ P-5 } & \multicolumn{6}{|c|}{ P-5B } & \multicolumn{4}{|c|}{ P-9B } & \multicolumn{5}{|c|}{ P-13 } \\
\hline & 50.054 & 50.239 & 49.931 & 49.783 & 50.020 & 48.063 & 48.243 & 48.207 & 48.259 & 48.066 & 47.421 & 47.895 & 47.124 & 47.780 & 47.670 & 48.131 & 48.059 & 46.674 & 48.373 & 48.219 \\
\hline $\mathrm{TiO}_{2}$ & 0.079 & 0.138 & 0.149 & 0.103 & 0.074 & 0.119 & 0.078 & 0.116 & 0.103 & 0.128 & 0.141 & 0.179 & 0.201 & 0.114 & 0.147 & 0.196 & 0.203 & 0.273 & 0.195 & 0.180 \\
\hline $\mathrm{Al}_{2} \mathbf{O}_{3}$ & 1.256 & 1.382 & 1.539 & 1.328 & 1.185 & 1.329 & 1.243 & 1.305 & 1.408 & 1.528 & 1.412 & 1.940 & 1.847 & 1.382 & 1.562 & 1.956 & 2.215 & 2.922 & 2.063 & 2.012 \\
\hline $\mathrm{Cr}_{2} \mathrm{O}_{3}$ & 0.006 & 0.006 & 0.014 & 0.002 & 0.000 & 0.007 & 0.000 & 0.000 & 0.004 & 0.014 & 0.000 & 0.014 & 0.013 & 0.002 & 0.012 & 0.000 & 0.000 & 0.000 & 0.000 & 0.005 \\
\hline $\mathrm{FeO}$ & 21.446 & 21.963 & 21.704 & 22.241 & 21.869 & 22.265 & 21.911 & 22.488 & 22.480 & 23.657 & 23.418 & 22.636 & 23.084 & 22.840 & 23.725 & 22.026 & 22.051 & 23.953 & 22.026 & 21.811 \\
\hline $\mathrm{Fe}_{2} \mathrm{O}_{3}$ & 0.000 & 0.000 & 0.000 & 0.000 & 0.000 & 0.000 & 0.000 & 0.000 & 0.000 & 0.000 & 0.000 & 0.000 & 0.000 & 0.000 & 0.000 & 0.000 & 0.000 & 0.000 & 0.000 & 0.000 \\
\hline MnO & 0.123 & 0.128 & 0.094 & 0.121 & 0.114 & 0.097 & 0.083 & 0.130 & 0.109 & 0.120 & 0.121 & 0.114 & 0.100 & 0.094 & 0.144 & 0.098 & 0.120 & 0.117 & 0.151 & 0.130 \\
\hline MgO & 5.537 & 5.176 & 5.217 & 5.113 & 5.523 & 5.903 & 6.150 & 6.050 & 6.038 & 5.515 & 5.463 & 5.389 & 5.137 & 5.741 & 5.616 & 5.822 & 5.848 & 6.044 & 5.913 & 6.077 \\
\hline $\mathrm{CaO}$ & 20.811 & 20.479 & 20.441 & 20.673 & 21.061 & 21.203 & 21.466 & 21.130 & 21.289 & 20.512 & 20.915 & 21.479 & 20.678 & 20.453 & 19.657 & 20.770 & 20.850 & 18.718 & 21.077 & 20.877 \\
\hline $\mathrm{Na}_{2} \mathrm{O}$ & 0.633 & 0.660 & 0.764 & 0.744 & 0.580 & 0.639 & 0.559 & 0.636 & 0.585 & 0.717 & 0.620 & 0.675 & 0.895 & 0.734 & 0.823 & 0.926 & 0.945 & 0.835 & 0.842 & 0.877 \\
\hline $\mathbf{K}_{2} \mathbf{O}$ & 0.004 & 0.000 & 0.014 & 0.000 & 0.000 & 0.000 & 0.007 & 0.000 & 0.003 & 0.009 & 0.000 & 0.041 & 0.013 & 0.002 & 0.008 & 0.000 & 0.000 & 0.023 & 0.004 & 0.006 \\
\hline Total & 99.949 & 100.171 & 99.867 & 100.108 & 100.426 & 99.625 & 99.740 & 100.062 & 100.278 & 100.266 & 99.511 & 100.362 & 99.092 & 99.142 & 99.364 & 99.925 & 100.291 & 99.559 & 100.644 & 100.194 \\
\hline Si & 1.980 & 1.984 & 1.978 & 1.975 & 1.975 & 1.929 & 1.931 & 1.927 & 1.925 & 1.925 & 1.917 & 1.912 & 1.912 & 1.930 & 1.926 & 1.921 & 1.911 & 1.880 & 1.916 & 1.917 \\
\hline $\mathbf{A l}^{\mathrm{IV}}$ & 0.020 & 0.016 & 0.022 & 0.025 & 0.025 & 0.063 & 0.059 & 0.062 & 0.066 & 0.072 & 0.067 & 0.088 & 0.088 & 0.066 & 0.074 & 0.079 & 0.089 & 0.120 & 0.084 & 0.083 \\
\hline $\mathrm{Al}^{\mathrm{VI}}$ & 0.039 & 0.049 & 0.050 & 0.037 & 0.030 & 0.000 & 0.000 & 0.000 & 0.000 & 0.000 & 0.000 & 0.004 & 0.000 & 0.000 & 0.000 & 0.013 & 0.015 & 0.019 & 0.013 & 0.012 \\
\hline $\mathbf{T i}$ & 0.002 & 0.004 & 0.004 & 0.003 & 0.002 & 0.004 & 0.002 & 0.003 & 0.003 & 0.004 & 0.004 & 0.005 & 0.006 & 0.003 & 0.004 & 0.006 & 0.006 & 0.008 & 0.006 & 0.005 \\
\hline $\mathrm{Fe}^{3+}$ & 0.000 & 0.000 & 0.000 & 0.000 & 0.000 & 0.000 & 0.000 & 0.000 & 0.000 & 0.000 & 0.000 & 0.000 & 0.000 & 0.000 & 0.000 & 0.000 & 0.000 & 0.000 & 0.000 & 0.000 \\
\hline $\mathrm{Cr}$ & 0.000 & 0.000 & 0.000 & 0.000 & 0.000 & 0.000 & 0.000 & 0.000 & 0.000 & 0.000 & 0.000 & 0.000 & 0.000 & 0.000 & 0.000 & 0.000 & 0.000 & 0.000 & 0.000 & 0.000 \\
\hline Mg & 0.326 & 0.305 & 0.308 & 0.302 & 0.325 & 0.353 & 0.367 & 0.360 & 0.359 & 0.329 & 0.329 & 0.321 & 0.311 & 0.346 & 0.338 & 0.346 & 0.347 & 0.363 & 0.349 & 0.360 \\
\hline $\mathrm{Fe}^{2+}$ & 0.710 & 0.725 & 0.719 & 0.738 & 0.722 & 0.747 & 0.733 & 0.752 & 0.750 & 0.792 & 0.792 & 0.756 & 0.783 & 0.772 & 0.801 & 0.735 & 0.733 & 0.807 & 0.730 & 0.725 \\
\hline Mn & 0.004 & 0.004 & 0.003 & 0.004 & 0.004 & 0.003 & 0.003 & 0.004 & 0.004 & 0.004 & 0.004 & 0.004 & 0.003 & 0.003 & 0.005 & 0.003 & 0.004 & 0.004 & 0.005 & 0.004 \\
\hline Ca & 0.882 & 0.867 & 0.868 & 0.879 & 0.891 & 0.912 & 0.921 & 0.905 & 0.910 & 0.880 & 0.906 & 0.919 & 0.899 & 0.885 & 0.851 & 0.888 & 0.889 & 0.808 & 0.895 & 0.889 \\
\hline $\mathrm{Na}$ & 0.049 & 0.051 & 0.059 & 0.057 & 0.044 & 0.050 & 0.043 & 0.049 & 0.045 & 0.056 & 0.049 & 0.052 & 0.070 & 0.057 & 0.064 & 0.072 & 0.073 & 0.065 & 0.065 & 0.068 \\
\hline
\end{tabular}

